\title{
Commercial Off-the-Shelf (COTS) Components and Enterprise Component Information System (eCIS)
}

Federal Manufacturing \& Technologies

John Minihan

Greg Enserro
Ed Schmidt

Melissa Thompson

\section{KCP-613-8421s}

Distributed June 2008

Topical Report on Enhanced Surveillance Program 703001

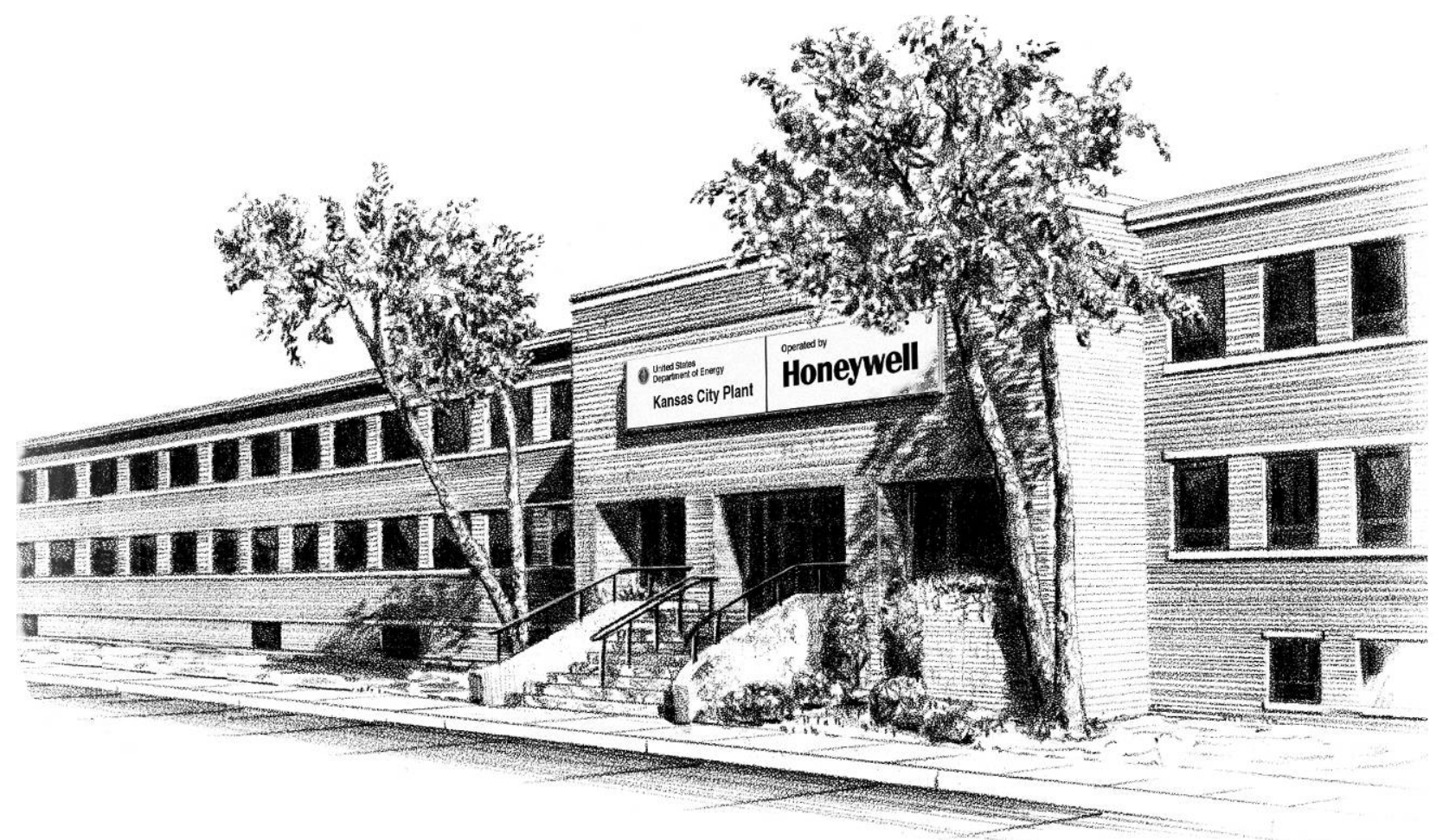

Prepared under prime contract DE-ACO4-01AL66850 for the

United States Department of Energy 


\section{DISCLAIMER}

This report was prepared as an account of work sponsored by an agency of the United States Government. Neither the United States Government nor any agency thereof, nor any of their employees, makes any warranty, express or implied, or assumes any legal liability or responsibility for the accuracy, completeness, or usefulness of any information, apparatus, product, or process disclosed, or represents that its use would not infringe privately owned rights. Reference herein to any specific commercial product, process or service by trade names, trademark, manufacturer, or otherwise, does not necessarily constitute or imply its endorsement, recommendation or favoring by the United States Government or any agency thereof. The views and opinions of authors expressed herein do not necessarily state or reflect those of the United States Government or any agency thereof.

All data analyzed and presented has been developed in a specific context of work and was prepared for internal evaluation and use pursuant to that work authorized under the reference contract. Reference herein to any specific commercial product, process or service by trade name, trademark, manufacturer, or otherwise, does not necessarily constitute or imply its endorsement, recommendation or favoring by the United States Government, any agency thereof or Honeywell Federal Manufacturing \& Technologies, LLC.

Printed in the United States of America.

This report has been reproduced from the best available copy.

Available to DOE and DOE contractors from the Office of Scientific and Technical Information, P.O. Box 62, Oak Ridge, Tennessee 37831; prices available from (865) 576-8401, FTS 626-8401.

Available to the public from the National Technical Information Service, U.S. Department of Commerce, 5285 Port Royal, Rd., Springfield, Virginia 22161, (703) 487-4650.

A prime contractor with the United States Department of Energy under Contract Number DE-AC04-O1AL66850
Honeywell Federal Manufacturing \& Technologies

P.O. Box 419159

Kansas City, Missouri, 64141-6159 
COMMERCIAL OFF-THE-SHELF (COTS) COMPONENTS AND ENTERPRISE COMPONENT INFORMATION SYSTEM (eCIS)

John Minihan

Distributed June 2008

Topical Report on Enhanced Surveillance Program 703001

John Minihan, Project Leader 



\section{Contents}

Section Page

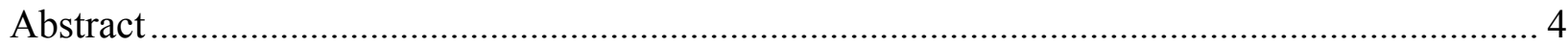

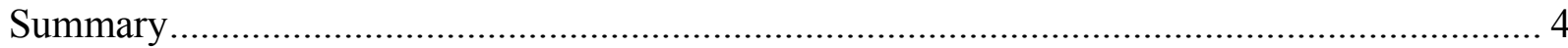

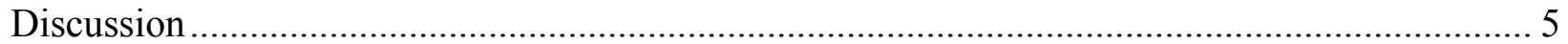

Scope and Purpose

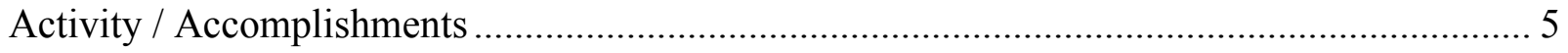

What is COTS?

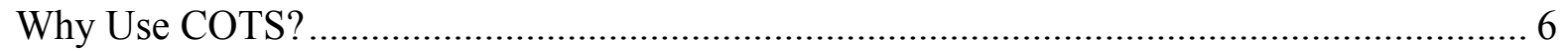

Risks of First Time COTS Usage........................................................................................... 8

War Reserve COTS Insertion Process (WRCIP) WRCIP Process Blocks .............................. 9

Risk Mitigation and Life of Program Buys (LOPB) ………………................................ 12

LOPB Cost Control and Risks Calculator........................................................................ 12

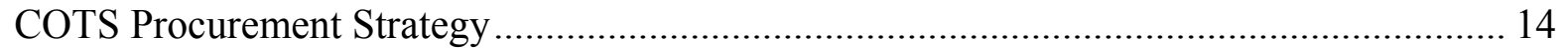

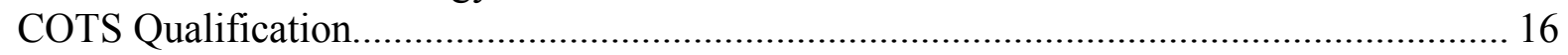

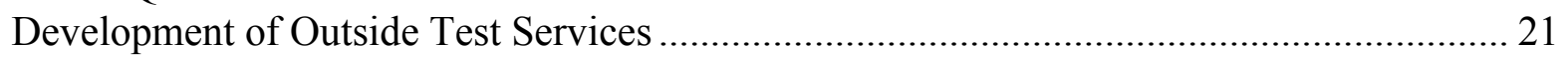

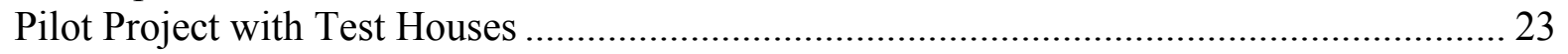

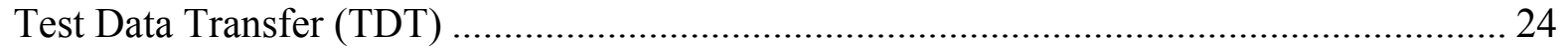

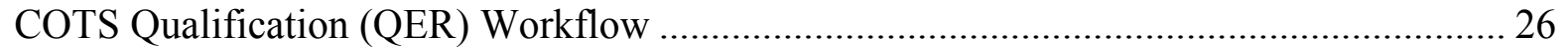

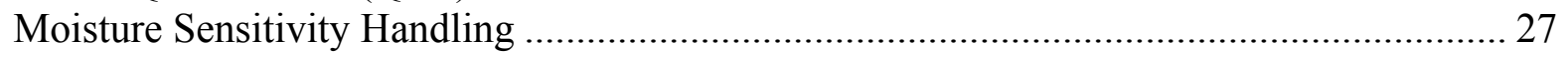

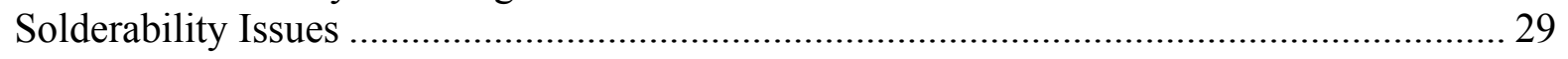

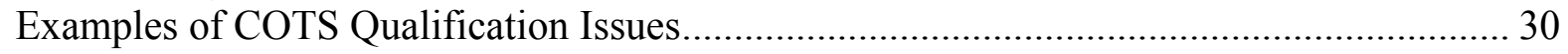

Enterprise Component Information System (eCIS) ………................................................ 32

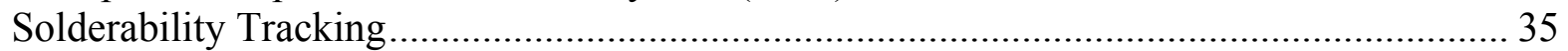

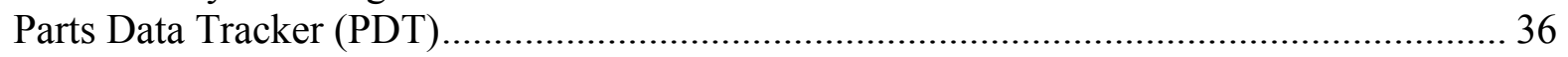

Bill of Material (BOM) Management …………………...................................................... 37

Quad Site CAD Library Part System ………………........................................................ 39

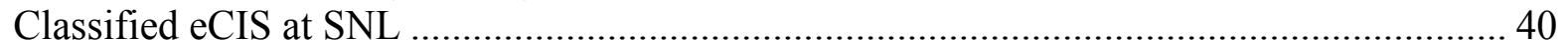

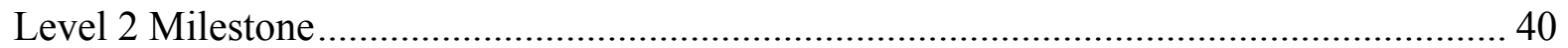

Purchased Products/Receiving Inspection Reporting ....................................................... 41

Computerized QRs, Computerized NCRs and Certified QRs.............................................. 41

Failure Analysis, Evaluation and Test Capabilities ............................................................. 43

Lessons Learned and What Worked Well......................................................................... 45

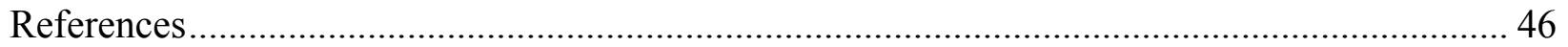

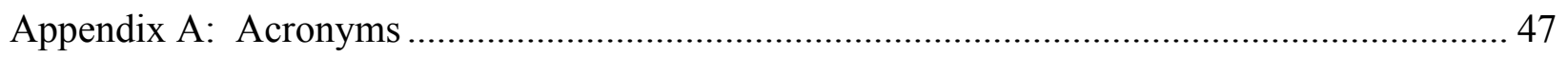

Appendix B: Outline Scope of Work for Outside Test House...................................................... 52

Appendix C: Technical Merit Factors for Test House Selection................................................... 54 


\section{Contents}

\section{Illustrations}

Figure Page

Figure 1. Example of hermetic parts ................................................................................. 5

Figure 2. Example of plastic parts ...................................................... Bookmark not defined.

Figure 3. Market Shares for Semiconductors vs. Users and Date ……..................................... 7

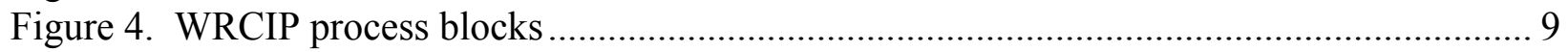

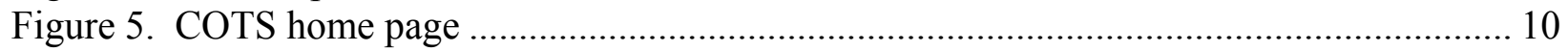

Figure 6. AER-to-qualification process with TBP and Command Media references................... 11

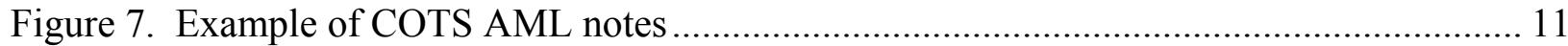

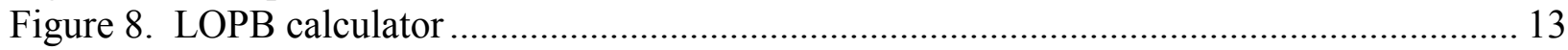

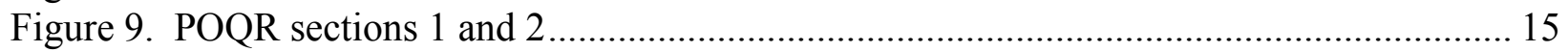

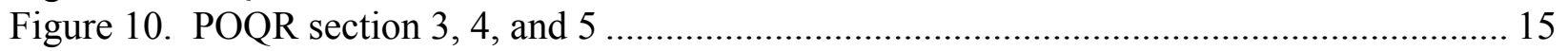

Figure 11. Typical qualification flow for semiconductors........................................................... 20

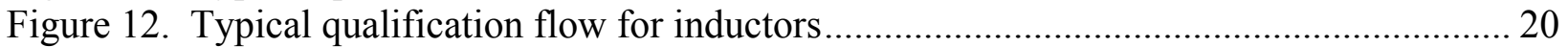

Figure 13. Data transfer from test house to eCIS....................................................................... 24

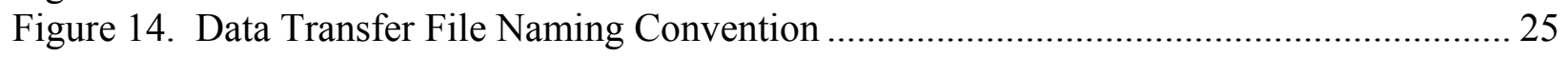

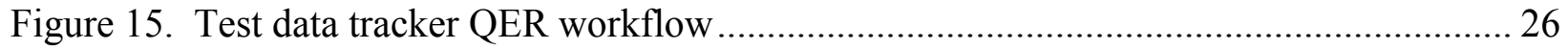

Figure 16. Acoustic images from SNL moisture experiment ................................................... 27

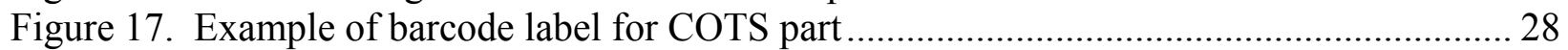

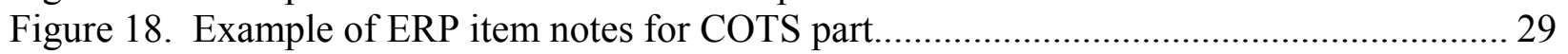

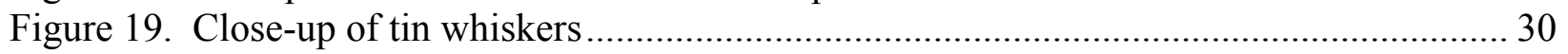

Figure 20. X-Ray of Bipolar Transistor LOPB Production Part................................................... 32

Figure 21. X-Ray of Bipolar Transistor Characterization Part ................................................. 32

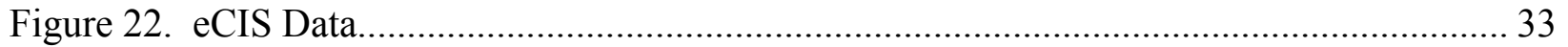

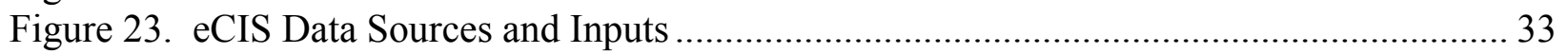

Figure 24. Supplier or Design Data to Customer......................................................................... 35

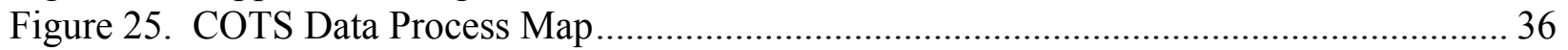

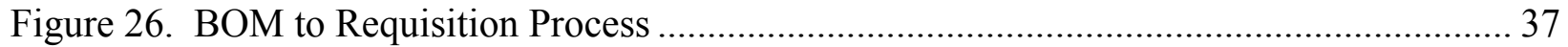

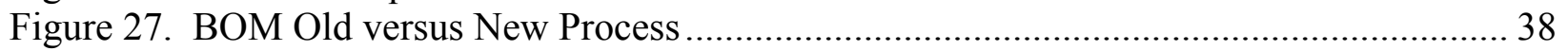

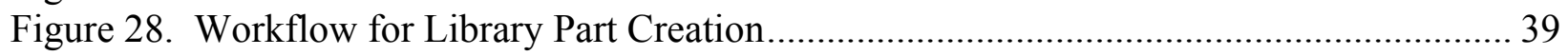

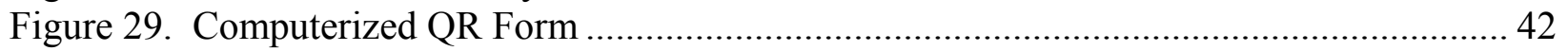




\section{Contents}

\section{Tables}

Number Page

Table 1. Examples of Differences Between Commercial and Mil-Spec Parts .......................... 8

Table 2. Quantities for LOPB and on-going parts by commodity ...................................... 14

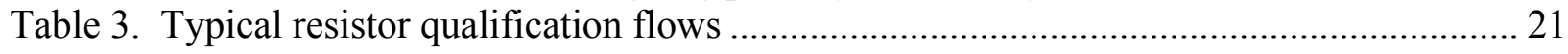

Table 4. Summary of COTS Qualification Issues .............................................................. 31 


\section{Abstract}

\section{Summary}

The purpose of the project was to develop the processes for using commercial off-the-shelf (COTS) parts for WR production and to put in place a system for implementing the data management tools required to disseminate, store, track procurement, and qualify vendors. Much of the effort was devoted to determining if the use of COTS parts was possible. A basic question: How does the Nuclear Weapons Complex (NWC) begin to use COTS in the weapon Stockpile Life Extension Programs with high reliability, affordability, while managing risk at acceptable levels?

In FY00, it was determined that a certain weapon refurbishment program could not be accomplished without the use of COTS components. The elements driving the use of COTS components included decreased cost, greater availability, and shorter delivery time. Key factors that required implementation included identifying the best suppliers and components, defining life cycles and predictions of obsolescence, testing the feasibility of using COTS components with a test contractor to ensure capability, as well as quality and reliability, and implementing the data management tools required to disseminate, store, track procurement, and qualify vendors. The primary effort of this project then was to concentrate on the risks involved in the use of COTS and address the issues of part and vendor selection, procurement and acceptance processes, and qualification of the parts via part and sample testing.

The Enterprise Component Information System (eCIS) was used to manage the information generated by the COTS process. eCIS is a common interface for both the design and production of NWC components and systems integrating information between SNL National Laboratory (SNL) and the Kansas City Plant (KCP). The implementation of COTS components utilizes eCIS from part selection through qualification release. All part related data is linked across an unclassified network for access by both SNL and KCP personnel. The system includes not only NWC part information but also includes technical reference data for over 25 Million electronic and electromechanical commercial and military parts via a data subscription. With the capabilities added to the system through this project, eCIS provides decision support, parts list/BOM analysis, editing, tracking, workflows, reporting, and history/legacy information integrating manufacturer reference, company technical, company business, and design data. 


\section{Discussion}

\section{Scope and Purpose}

The purpose of the project was to develop the processes for using commercial off-the-shelf (COTS) parts for two weapon Stockpile Life Extension Programs (SLEP) and to put in place a system for implementing the data management tools required to disseminate, store, track procurement, and qualify vendors. Much of the effort was devoted to determining if the use of COTS parts was possible. A basic question: How does the Nuclear Weapons Complex (NWC) begin to use COTS in the weapon SLEP's with high reliability, affordability, while managing risk at acceptable levels?

\section{Activity / Accomplishments}

\section{What is COTS?}

Commercial off-the-shelf (COTS) parts are parts/components where no special requirements are imposed by the buyer. COTS parts are considered catalog items. For purchased electrical components, COTS may include commercial grade $\left(0^{\circ} \mathrm{C}\right.$ to $+70^{\circ} \mathrm{C}$, plastic encapsulated microcircuits (PEMs)), industrial grade $\left(-40^{\circ} \mathrm{C}\right.$ to $+85^{\circ} \mathrm{C}$, PEMs or ceramic/metal can hermetic), or military grade $\left(-55^{\circ} \mathrm{C}\right.$ to $+125^{\circ} \mathrm{C}$, usually ceramic/metal can hermetic).

COTS results in a new procurement methodology and a design philosophy. Specifically, emphasis changes from routine design to picking the right part for the intended application. In addition, the part requirements must be validated, and parts must be qualified for end use. COTS are not meant to be buy and fly.

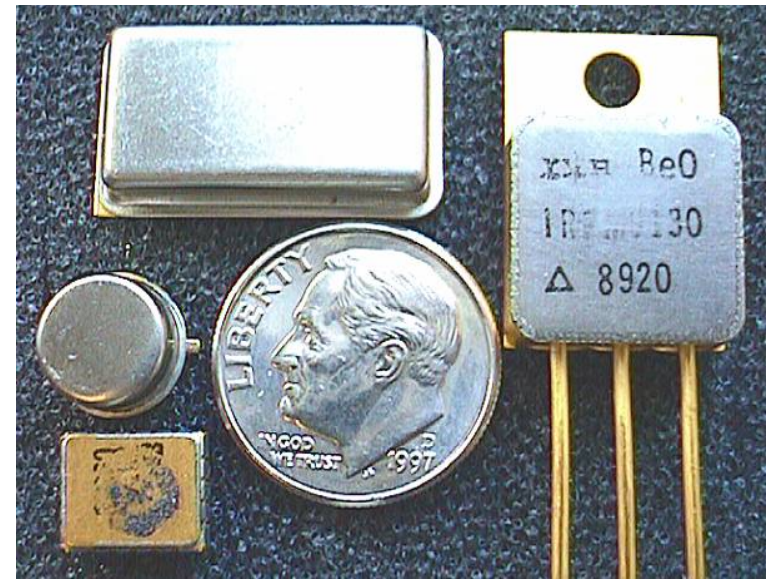

Figure 1. Example of hermetic parts

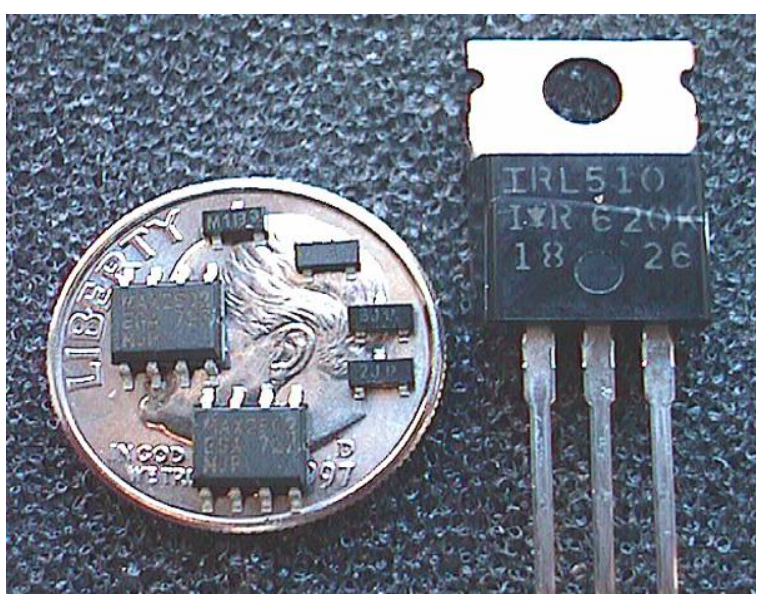

Figure 2. Example of plastic parts 


\section{Why Use COTS?}

In FY00, it was determined that the refurbishment of a certain weapon could not be accomplished without the use of COTS components. The drivers for using COTS included:

- Quarter cost AFS (Arming Fusing Subsystem)

- Diminishing manufacturing sources

- Greater availability of plastic parts over military grade hermetic parts

- Lower part cost

- Smaller weight and volume

- Greater functionality

- Schedule and availability of parts off-the-shelf

As stated earlier, the main problem and largest business impact revolved around the question of how the NWC could begin to use COTS in two weapon Stockpile Life Extension Programs with high reliability, affordability, while managing risk at acceptable levels. To do this, the following needed to be set up:

1. Identify the selection of the best components and suppliers

2. Formulate component life cycle and obsolescence prediction tools

3. Implement the test subcontractor capability to perform qualification and reliability testing of COTS

4. Implement data management tools to disseminate, store, track progress of the procurement and qualification

5. Implement KCP COTS failure analysis capabilities and infrastructure

The market for military parts, in particular parts called out by source control drawings, diminished greatly since the mid-1980s (Figure 3). Manufacturers who worked to source control drawings 10 to 20 years ago no longer accept orders to customer requirements. 


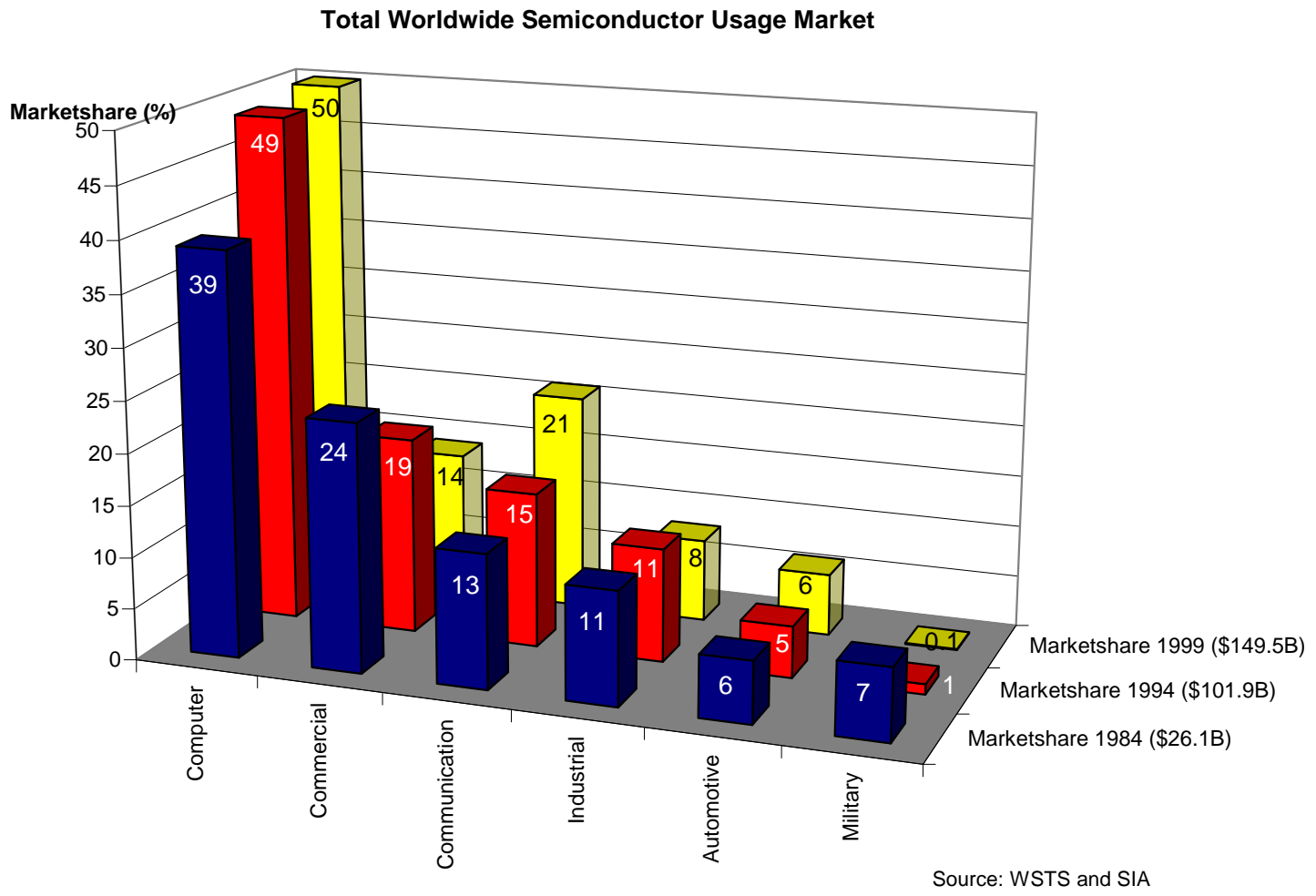

Figure 3. Market Shares for Semiconductors vs. Users and Date

Manufacturers of electrical components are being driven by the computer and cell phone industry. This actually allows for a higher quality part as processes are geared for manufacturing of hundreds of thousands of parts versus just hundreds of parts. New products are constantly being introduced in plastic packages allowing for more flexibility and functionality in design. Parts are smaller in size and weight which appeals to the designers. As a result, COTS parts typically have a higher degree of availability and lower purchasing costs.

Table 1 shows actual costs for COTS parts with comparisons noted between Commercial and Mil-Spec. For the diodes, transistors and MOSFETs, the cost difference is more typical of what is seen in a comparison of Commercial and Mil-Spec. In the case of resistors and capacitors, Commercial parts ended up showing a higher total cost because the Commercial level is all that is available for certain difficult-to-manufacture values. 
Table 1. Examples of Differences Between Commercial and Mil-Spec Parts

\begin{tabular}{|c|c|c|c|c|c|c|c|}
\hline \multicolumn{2}{|c|}{ Part Type } & $\begin{array}{l}\text { Part } \\
\text { Type } \\
\text { Qty }\end{array}$ & $\begin{array}{l}\text { Procure Price } \\
\text { Range Each }\end{array}$ & $\begin{array}{l}\text { Typical } \\
\text { Price } \\
\text { Each }\end{array}$ & $\begin{array}{l}\text { Qualification } \\
\text { Lot Cost }\end{array}$ & $\begin{array}{l}\text { Radiation } \\
\text { Lot Cost }\end{array}$ & $\begin{array}{l}\text { Total Cost } \\
\text { for } 10 \mathrm{~K} \\
\text { Lot Size }\end{array}$ \\
\hline \multirow{2}{*}{ Diodes } & Commercial & 20 & $\$ 0.01-1.21$ & $\$ 0.03$ & $\$ 22,000$ & $\$ 25,000$ & $\$ 47,300$ \\
\hline & Mil-Spec & 15 & $\$ 4.22-47.65$ & $\$ 7.50$ & $\$ 8,000$ & $\$ 25,000$ & $\$ 108,000$ \\
\hline \multirow{2}{*}{ Transistors } & Commercial & 6 & $\$ 0.01-0.17$ & $\$ 0.03$ & $\$ 38,000$ & $\$ 25,000$ & $\$ 63,300$ \\
\hline & Mil-Spec & 4 & $\$ 1.40-8.00$ & $\$ 8.00$ & $\$ 8,000$ & $\$ 25,000$ & $\$ 113,000$ \\
\hline \multirow[b]{2}{*}{ MOSFET } & Commercial & 2 & $\$ 0.34-0.86$ & $\$ 0.86$ & $\$ 31,000$ & $\$ 25,000$ & $\$ 64,600$ \\
\hline & Mil-Spec & 2 & $\begin{array}{c}\$ 305.00- \\
377.45 \\
\end{array}$ & $\$ 377.45$ & $\$ 12,000$ & $\$ 25,000$ & $\begin{array}{r}\$ 3,811,50 \\
0 \\
\end{array}$ \\
\hline $\begin{array}{c}\text { RF } \\
\text { Devices }\end{array}$ & Commercial & 17 & $\$ 0.22-10.00$ & $\$ 1.80$ & $\$ 57,000$ & $\$ 25,000$ & $\$ 100,000$ \\
\hline IC & Commercial & 5 & $\$ 0.10-3.45$ & $\$ 2.60$ & $\$ 45,000$ & $\$ 25,000$ & $\$ 96,000$ \\
\hline Inductors & Commercial & 34 & $\$ 0.09-4.45$ & $\$ 0.09$ & $\$ 5,000$ & 0 & $\$ 5,900$ \\
\hline \multirow{2}{*}{ Resistors } & Commercial & 10 & $\$ 0.71-2.39$ & $\$ 1.01$ & $\$ 5,000$ & 0 & $\$ 15,100$ \\
\hline & Mil-Spec & 153 & $\$ 0.41-5.30$ & $\$ 0.58$ & $\$ 1,000$ & 0 & $\$ 6,800$ \\
\hline \multirow{2}{*}{ Capacitors } & Commercial & 5 & $\$ 0.81-12.27$ & $\$ 10.00$ & $\$ 5,000$ & 0 & $\$ 105,000$ \\
\hline & Mil-Spec & 66 & $\$ 0.77-9.80$ & $\$ 2.37$ & $\$ 1,000$ & 0 & $\$ 24,700$ \\
\hline
\end{tabular}

\section{Risks of First Time COTS Usage}

A number of risks were identified with the use of COTS in War Reserve (WR) applications. Some priority risks were:

- Lack of history - There is no baseline for using plastic, non-hermetic components in WR applications. No history exists for storage life, reliability, radiation response, long term material compatibility, failure rate, and failure modes.

- Component life cycles - the Component lifecycle for plastic parts is two-to-five years. This lifecycle is not compatible with NWC programs.

- Early funding availability - The availability of funding for Life of Program Buys (LOPB) where LOPB's are used to mitigate the short component life cycle and provide homogeneity within the component material.

- Manufacturer oversight - There is no control over the COTS manufacturers. Procurement would primarily be through distributors without the use of source-controlled drawings. Manufacturers can change materials, processes (e.g., die shrinks) and locations at any time without notification.

- Subcontractor testing - We would rely on a subcontractor to perform qualification testing. New equipment required for testing plastic parts is very capital and labor intensive. 
The processes and tools implemented by this COTS project helped to mitigate these risks. During the course of the project, lack of funding over fiscal years allowed for a possible decision to perform multiple buys and delay qualification of COTS components. This put them at risk of obsolescence and variability over time due to changes in design, materials, manufacturing process, and location. Those items in commodities with the highest risk were identified and set up for LOPB and qualification. As a result of the work done by the War Reserve COTS Insertion Process (WRCIP) team to identify risks, funding was eventually available to allow all necessary LOPB and qualification activities to take place. Without the decision to continue with LOPB and qualification, increase in total costs and a slip in delivery of the First Production Unit (FPU) for the program would have resulted.

\section{War Reserve COTS Insertion Process (WRCIP) Process Blocks}

The WRCIP was formed jointly with SNL National Laboratory (SNL) to develop a process to supply COTS parts for WR applications. The process was refined and broken into 5 main sections (Figure 4).

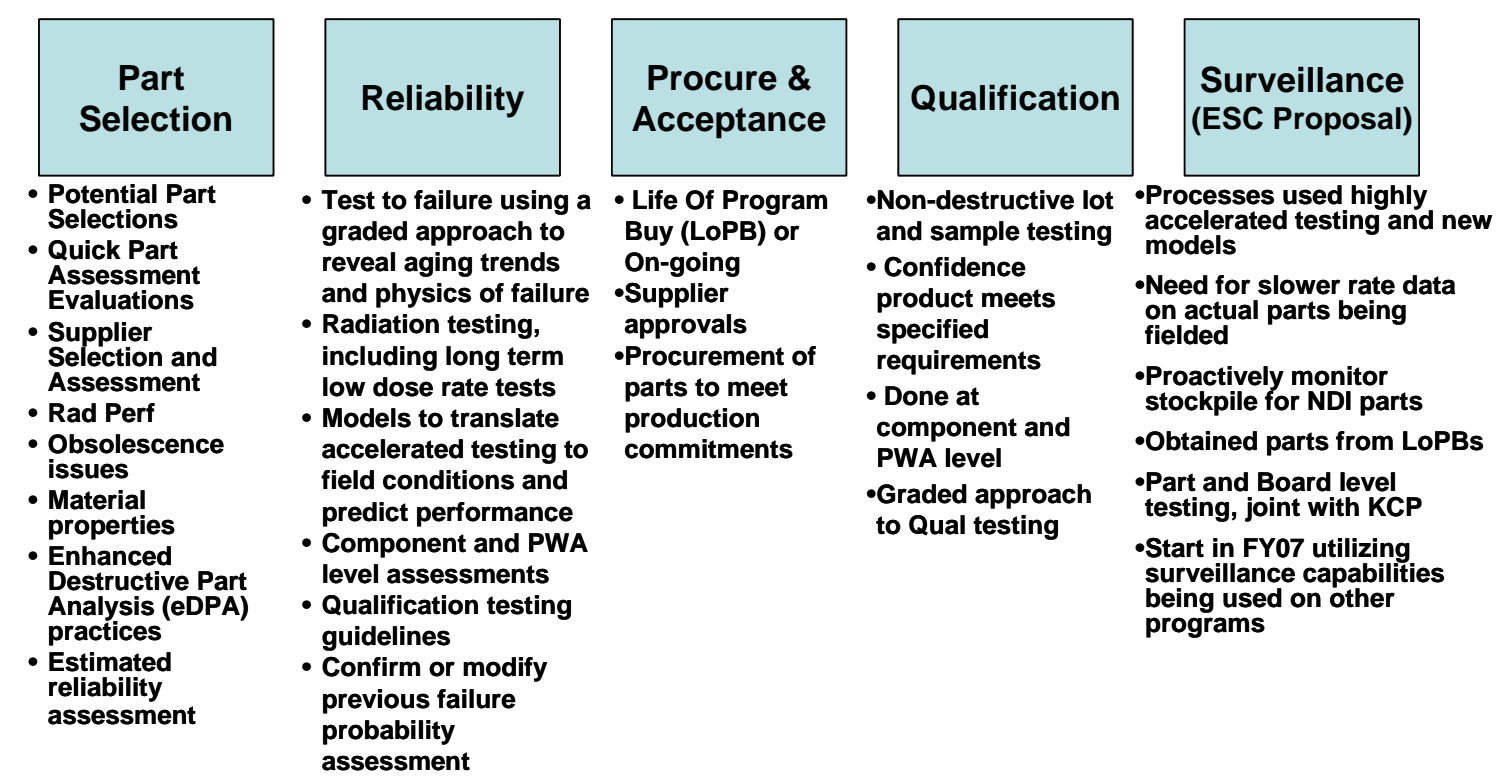

Figure 4. WRCIP process blocks

The Part selection, Reliability, and Surveillance blocks were primarily SNL functions. The qualification block was a joint SNL-KCP function while the Procure and Acceptance block was primarily a KCP function. Procure \& Acceptance and Qualification were defined in the product specification (PS) drawings. Processes used for qualification were documented in Special Use (SS) Specifications. Tools for the processes were implemented utilizing the Enterprise Component Information System (eCIS). Detailed process descriptions of the WRCIP 5-block approach is contained within the COTS homepage (Figure 5). 


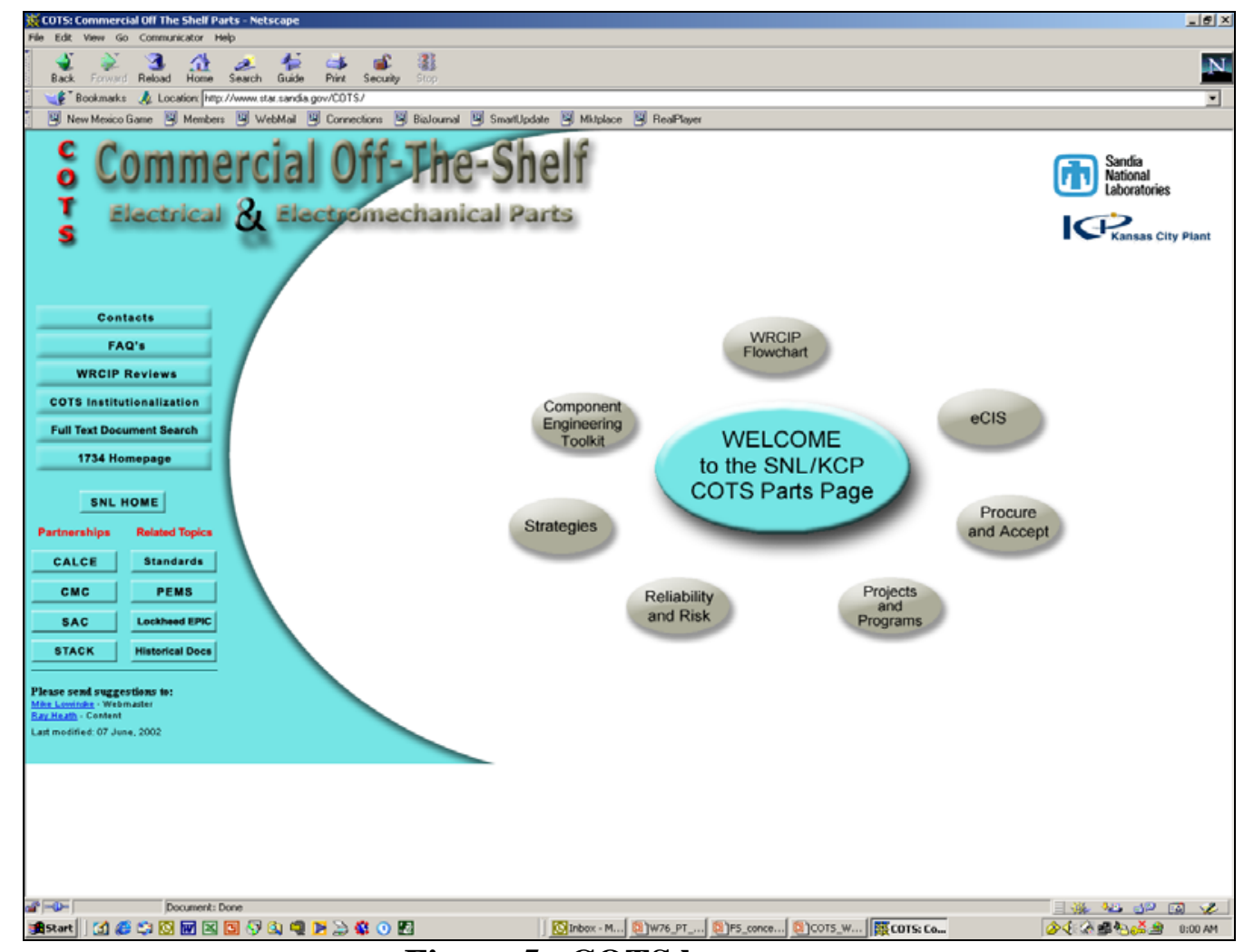

Figure 5. COTS home page

A high level block diagram for the Procure and Accept and Qualification functions is provided in Figure 6. below. An Advance Engineering Release (AER) for the assembly (User AER) is released to indicate the parts that are to be used. Part Engineering Releases (ERs) such as AER's, Drawing Transfer Engineering Releases (DTER's), and Special Instruction Engineering Releases for B items (SIER/B) are released to allow KCP to begin the process to buy the parts. KCP releases the Automatic Material List (AML) and sets up the item (part) in PeopleSoft (ERP). Once the item is set up and the AML released, the Purchase Order Quality Requirements (POQR) and MES (Manufacturing Execution System) routings (inspection instructions) are released. The User AER and Part ERs trigger input to the LOPB calculator to determine quantities needed. Once the quantities are agreed to and have appropriate approvals, a sales order is entered to drive the demand for the parts. For on-going buys, a sales order is entered to drive the initial demand, with ERP (Enterprise Resource Planning) to drive the demand for the remainder of the quantities needed.

The SIER/B's designate the manufacturers for the parts. Purchase orders are placed with manufacturers or authorized distributors for the manufacturer. Parts are either shipped to KCP or shipped directly to a designated outside test house. Parts begin qualification once a Product Specification and Complete Engineering Release (CER) are released. Once Qualification testing is completed, successful results end up with an acceptable Qualification Evaluation Release (QER) and with parts going to stores and made available to the using assembly. 


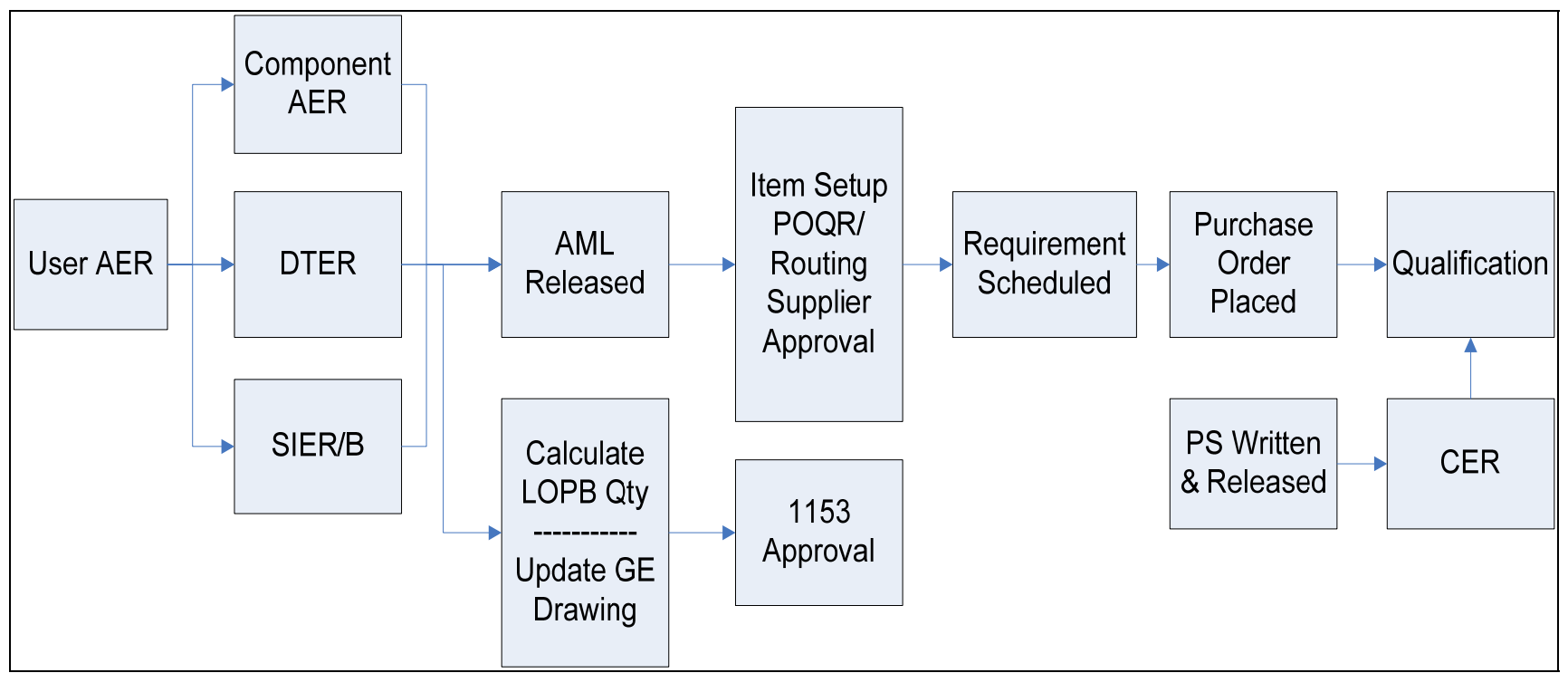

Figure 6. AER-to-qualification process with TBP and Command Media references

AML's are typically released at KCP and have notes similar to those in the Figure 7. below. The AML states that the part is a COTS part (catalog item) and drives procurement to the manufacturer's part number. The part can be purchased through the manufacturer or an authorized distributor of the manufacturer. An authorized distributor is a distributor designated by the manufacturer to sell product for the manufacturer and where the product's origin and legitimacy can determined. Typically, the manufacturer will require that COTS parts be purchased through their authorized distributors and will not sell directly to a buyer.

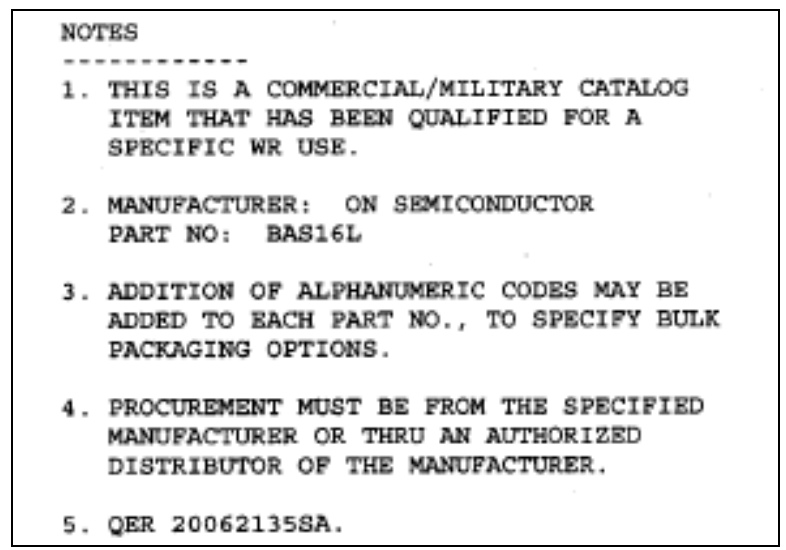

Figure 7. Example of COTS AML notes 


\section{Risk Mitigation and Life of Program Buys (LOPB)}

A key risk mitigation was the implementation of Life of Program Buys (LOPB). LOPB results in reduced risk of variability since lots are more likely to be a single date code or consecutive date codes, and the manufacturing processes and materials used are less likely to have changes. LOPB is the key to consistent and predictable performance and radiation responses. LOPB also reduces the risk of obsolescence. The typical component lifecycle is 2-5 years. A program development/production phase for a weapon application may last 10-15 years. LOPB eliminates the potential for system or subsystem redesign due to a component not being available due to obsolescence. Changes in industry, in particular the change to lead-free solder finish, also drive LOPB. During the procurement and acceptance of components, several manufacturers went through the process to convert to lead-free solder finish.

Constraints to LOPB included availability of funding due to program phasing, continuing resolutions and potential capacity overload. Typically, the cost of COTS parts is significantly less than Mil-Spec and the legacy Source Control (SCD) parts, so early procurement of parts could be justified. By going to COTS, resources previously spent setting up suppliers could be better utilized in preparation for qualification test activities. Other risks for utilizing LOPB involve design maturity and lack of recovery time if problems were detected on the LOPB material. Much oversight was given to SNL releases involving changes to LOPB parts. Less than $1 \%$ of parts originally purchased against the design went unqualified.

LOPB is the key to cost control. Qualification testing, radiation testing, and reliability assessments are sample-based destructive tests. Samples represent the procurement lot. Future procurements are assumed to be different due to probable changes in design, process, materials or manufacturing location. Qualification testing (and its expense) is likely to be repeated when future procurements are made. Component costs are typically small compared to testing costs, with minimum buy quantities sometimes satisfying programmatic requirements.

Conducting LOPB as early as possible allows for workload leveling between engineering (KCP and SNL), Buyers, and Drafting. Recovery time is also available in the event of a failure during lot testing.

\section{LOPB Cost Control and Risks Calculator}

A tool was needed to determine the number of parts to order for LOPB. The calculator was designed to build in the production deliverables with D-test, attrition rates, and any samples needed (e.g., qualification, enhanced surveillance). Bulk packaging was taken into account, and the number of reels to order calculated. A General Engineering (GE) drawing was released to document the quantities to be ordered. 


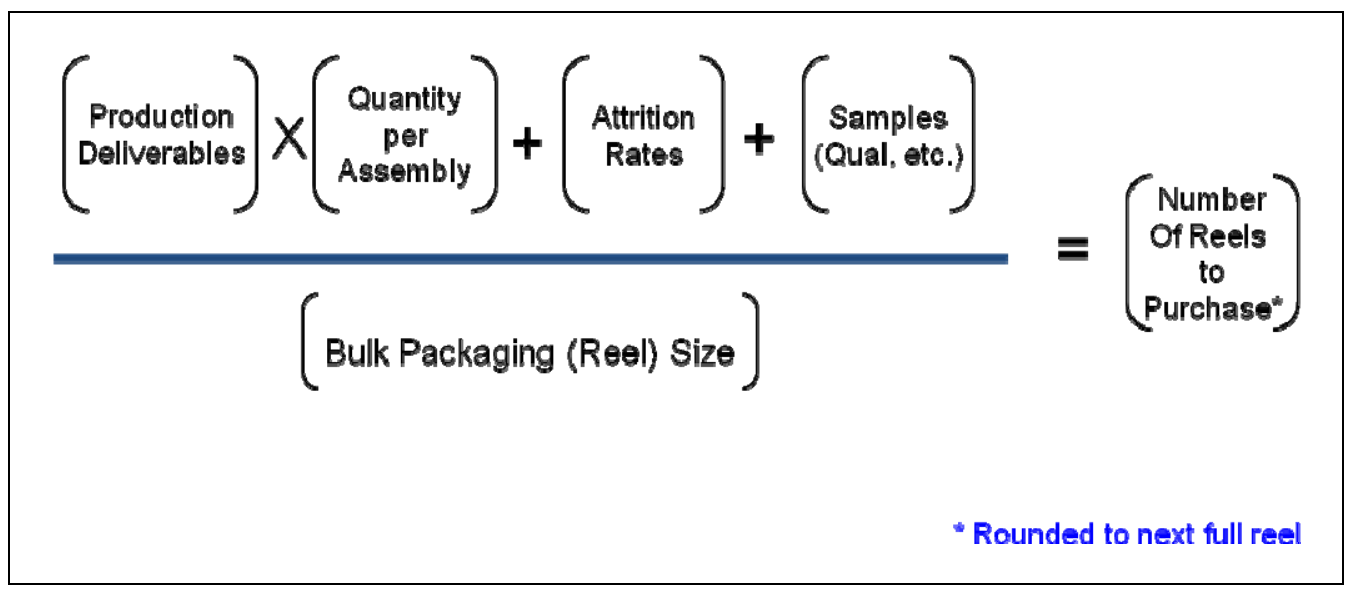

Figure 8. LOPB calculator

Not all electronic components were set up as LOPB. Some were set up as "on-going." The strategy and prioritization used to determine the phasing for ordering parts involved several factors:

The factors for on-going versus LOPB include:

- Visibility/detectability of change

- Visibility/predictability of obsolescence

- Past experience

- Criticality to design

- Qualification cost

The factors for prioritization include:

- Sufficient work completed to write component AER in FY04

- Confidence in being in final design

- Criticality to design

- Likelihood of change to materials, process, design

- Likelihood of obsolescence

- Budget constraints

- Schedule needs

The commodities identified for LOPB included semiconductors, inductors, some capacitors and resistors (commercial, tantalum, radiation sensitive). Those identified for on-going procurements included most capacitors, military resistors and a couple of SCD parts. 
Table 2. Quantities for LOPB and on-going parts by commodity

\begin{tabular}{|l|l|c|c|}
\hline \multicolumn{2}{|c|}{ COMMODITY } & $\begin{array}{c}\text { LOPB PARTS } \\
(\mathbf{2 0 0 4 - 2 0 0 5 )}\end{array}$ & ON-GOING PARTS \\
\hline & & & 1 \\
\hline Semiconductors & Diode & 56 & 1 \\
\hline & IC & 21 & 5 \\
\hline & FET/MOSFET & 14 & 1 \\
\hline & RF & 25 & 0 \\
\hline & Transistor & 15 & 93 \\
\hline Capacitors & & 12 & 278 \\
\hline Resistors & & 17 & 0 \\
\hline Inductors & & 39 & \\
\hline
\end{tabular}

\section{COTS Procurement Strategy}

Component purchases were worked in procurement groups. The procurement strategy was put in place to help mitigate the identified risks and to level out the workload and funding. Actions to provide a balanced workload necessitated the need to align the procurements such that the following resources were taken into account:

- At KCP - Component Engineering, Drafting, Purchasing

- At SNL - Component Engineering, Design Engineering

- At Test House - Test Software \& Hardware Production, Testing

Purchase Order Quality Requirements (POQR) document the requirements imposed on the supplier (manufacturer or authorized distributor). The POQR addressed the mitigation risk of counterfeit parts and part / supplier variability by designating the procurement to the manufacturer or an authorized distributor to the manufacturer. Additionally, date code restrictions were implemented to reduce lot to lot variability.

A typical POQR for COTS parts is shown in Figures 9 and 10 below. The POQR lists the supplier program to be imposed on the supplier. PQR 1010, Supplier Program II, typically requires no on-site audit, and approval is based on a checklist questionnaire validated by phone, fax, or e-mail. PQR 1030, Use of Third Party Approvals typically requires no on-site audit, and approval is based on evaluations by US government or independent technical organizations, e.g., DSCC, ISO. A prior on-site PQR 1020 or higher is required to allow a PQR 1030. 


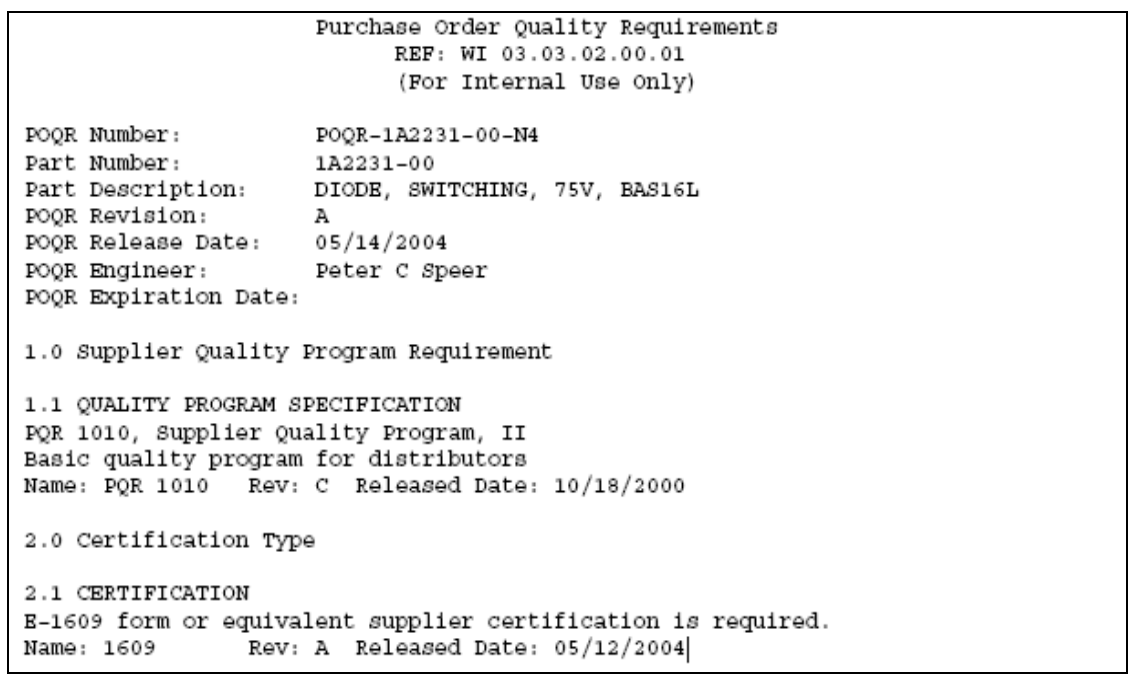

Figure 9. POQR sections 1 and 2

The body of the POQR contains the quality or other special requirements imposed on the product. The required manufacturer and manufacturer's part number are called out. The manufacturer's part number may have additional characters to note specific bulk packaging or solder finish requirements. The buyer information gives the Buyer instructions that may not appear in the Purchase Order. Instructions to the Buyer to drop ship material to an outside test house were placed here.



Figure 10. POQR section 3, 4, and 5 


\section{COTS Qualification}

COTS are often thought of as plastic parts, and indeed are a substantial subset of the COTS used. Plastic Encapsulated Microelectronics (PEM's) have not been used in previous WR applications. PEMs are not typically designed for or tested to military conditions. There is no baseline or experience with PEMs. Other high-reliability/military users of COTS/PEMs perform and recommend qualification of components to the intended application. These users include NASA, JPL, NAVSEA to name a few.

Lessons learned from past programs stressed the importance of qualification. Considerations were taken for driving qualification to the highest level possible, such as printed wiring assembly (PWA) or subsystem (only when this makes sense to do). Qualifying the parts at the component level using a minimum suite of tests that could be tailored to the different commodities (integrated circuits, diodes, resistors, capacitors, etc.) seemed like a good approach. Several options were considered prior to the start of qualification activities. These options have noted advantages and disadvantages.

1. Perform qualification at the board level with no qualification at component level. This results in the highest risk but with lowest short term cost:

a. Advantages are the reduction of short term costs and component lead times for procurement and acceptance.

b. Disadvantages are the risks taken at the board level. There would be increased board level qualification costs, a redesign effort to provide access test points (also increasing board volume), and tester changes to test component parameters. All components would not be accessible at the board level. No component level QER's would be available.

2. Perform qualification at the component level by similarity. Components may be grouped based on similar characteristics (supplier, package style, country of origin, etc) and representative samples would undergo qualification testing. This option builds on existing strategies but caution is recommended based on past experience.

a. Advantages are a lower risk at the board level and the potential to reduce qualification costs by $20-40 \%$. Qualification by similarity is used in industry, and there is already a plan to purchase certain commodities in families (resistors, diodes, capacitors, e.g.). This method could apply to follow-on procurements that have multiple buys.

b. Disadvantages include the affect on multiple part numbers by a qualification failure and the loss of time on the remaining family part numbers. Similarities are assumed among component groupings that may not exist. There is an inability to budget and plan using this option. 
3. Perform qualification at the component level on initial procurements only. No component level qualification performed on follow-on procurements.

a. Advantages include the reduction in total program cost. This is a common practice in industry where frequent purchases are made. This provides less risk than no qualification.

b. Disadvantages include the lack of quality evidence that subsequent procurements are the same.

4. Perform reduced qualification testing at the component level where some tests are eliminated for certain parts. This provides some cost relief but would take the level of testing below the minimum considered for qualification.

a. Advantages include short-term cost relief and possible reduction in component lead times. This option could work with qualification by similarity.

b. Disadvantages include the inability to detect some changes using Destructive Physical Analysis (DPA) alone (e.g., diffusion, implant). Current qualification testing is considered a minimum.

5. Perform board level qualification for low risk items such as Mil-Spec resistors or capacitors. This appears to be the lowest risk of all options but will also garner the smallest reward.

a. Advantages are that this is the lowest risk.

b. Disadvantages are that minimum qualification is already planned for Mil-Spec resistors and capacitors.

The approach taken was to use a combination of these options based on the pedigree of the parts and associated risks. There was a level of risk accepted at the board level and testing such as HALT (Highly Accelerated Life Testing) and HASS (Highly Accelerated Stress Screening) were implemented to detect any weak parts. Family qualifications were implemented where they best fit. All COTS components received some level of qualification. 
Qualification and acceptance process support drawings were developed for COTS parts. These include the following

- $\quad$ SS1A2945 - Qualification and Reliability Testing

- This specification defines the qualification and reliability test requirements for commercially available electronic parts.

- SS1A2944 - Radiation Qualification Testing

- This specification defines the requirements for radiation testing of commercially available electronic parts.

- SS1A3023 - Pulling Samples for LOPB Testing

- This document defines the requirements for handling, sample selection and storage of commercially available electrical components prior to acceptance into production stores. Type A samples are those selected in the most convenient method. Type Q samples are those selected from entire population from multiple location (front and back of reel for reels $<3500$ ).

- $\quad$ SS1A3022 - Tinning of Leads (if required)

- This specification defines the minimum requirements for the performance of hot $\mathrm{Sn}-\mathrm{Pb}$ solder dipping of components which have either lead-free terminals or gold lead terminations.

- $\quad$ SS1A2073 - Enhanced Destructive Physical Analysis

- This document defines the minimum requirements for Enhanced Destructive Physical Analysis (eDPA) of Plastic Encapsulated Microcircuits (PEMs) and plastic discrete devices (diodes, transistors, etc.).

- $\quad$ SS1A2074 - C-mode Scanning Acoustical Microscope (CSAM) Testing

- This document defines the minimum requirements for the acoustic microscopy analysis of non-hermetic encapsulated electronic components.

In addition to specific part drawings and SS specifications, many industry specifications for storage and assembly of plastic parts and assembled boards were utilized. Examples of industry standards include:

- IPC/JEDEC J-STD-033A:

- Joint IPC/JEDEC Standard: Handling, Packing, Shipping and Use of Moisture/Reflow Sensitive Surface Mount Devices

- IPC/JEDEC J-STD-020B:

- Joint IPC/JEDEC Standard: Moisture Sensitivity Classification

- JESD22-A112 (replaced by J-STD-020B):

- JEDEC Standard: Moisture-Induced Stress Sensitivity for Plastic Surface Mount Device

- JESD22-A113:

- JEDEC Standard: Preconditioning of Plastic Surface Mount Device 
Acceptance testing was greatly reduced from previous programs with more reliance placed on DPA and Construction Analysis (CA). Since the majority of parts are LOPB, emphasis was placed on the qualification testing. No $100 \%$-acceptance testing was imposed at the component level. Sample functional and radiation testing was performed for qualification. Testing was driven to the highest level possible, i.e., PWA or higher. We would expect some level of failures at the next assembly level, typically less than $1 \%$. It may not be feasible to do failure analysis on each part failure.

Typical qualification tests for active COTS parts include (See Figure 11 for flow):

- HAST (350 Hours)

- Temp Cycle (1000 cycles)

- Temp Shock (100 cycles)

- Pre-conditioning

- Electrical Testing

- CSAM

- DPA/CA

- Post HAST Bond Pull

- Solderability

- Radiation

Typical qualification tests for passive COTS parts include (See Figure 12 for inductor flow):

- Temp Cycle (1000 cycles)

- Temp Shock (100 cycles)

- High Temperature Operation Life (HTOL)

- Electrical Testing

- CSAM

- DPA

- Solderability

- Radiation (some capacitors) 


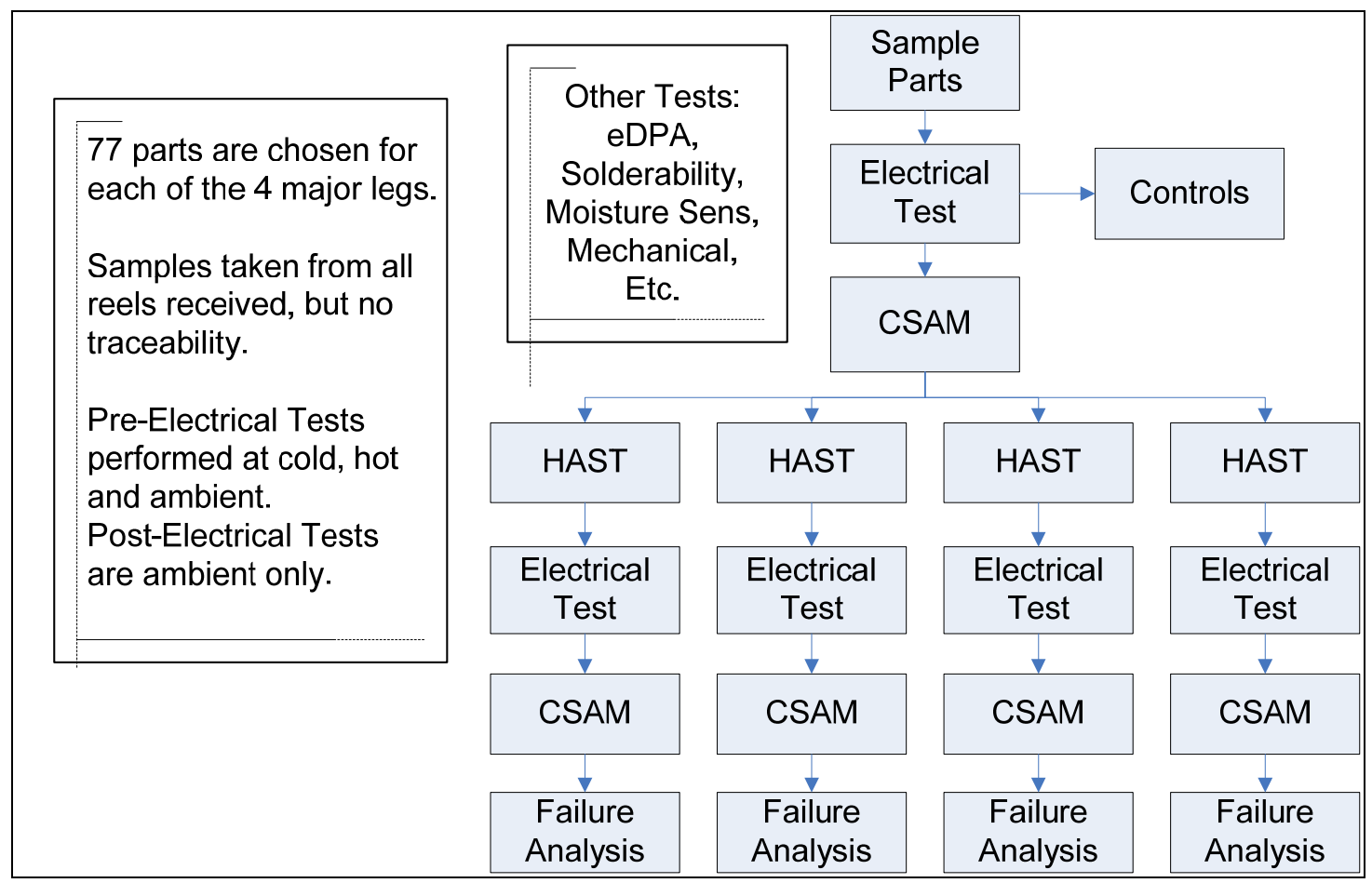

Figure 11. Typical qualification flow for semiconductors

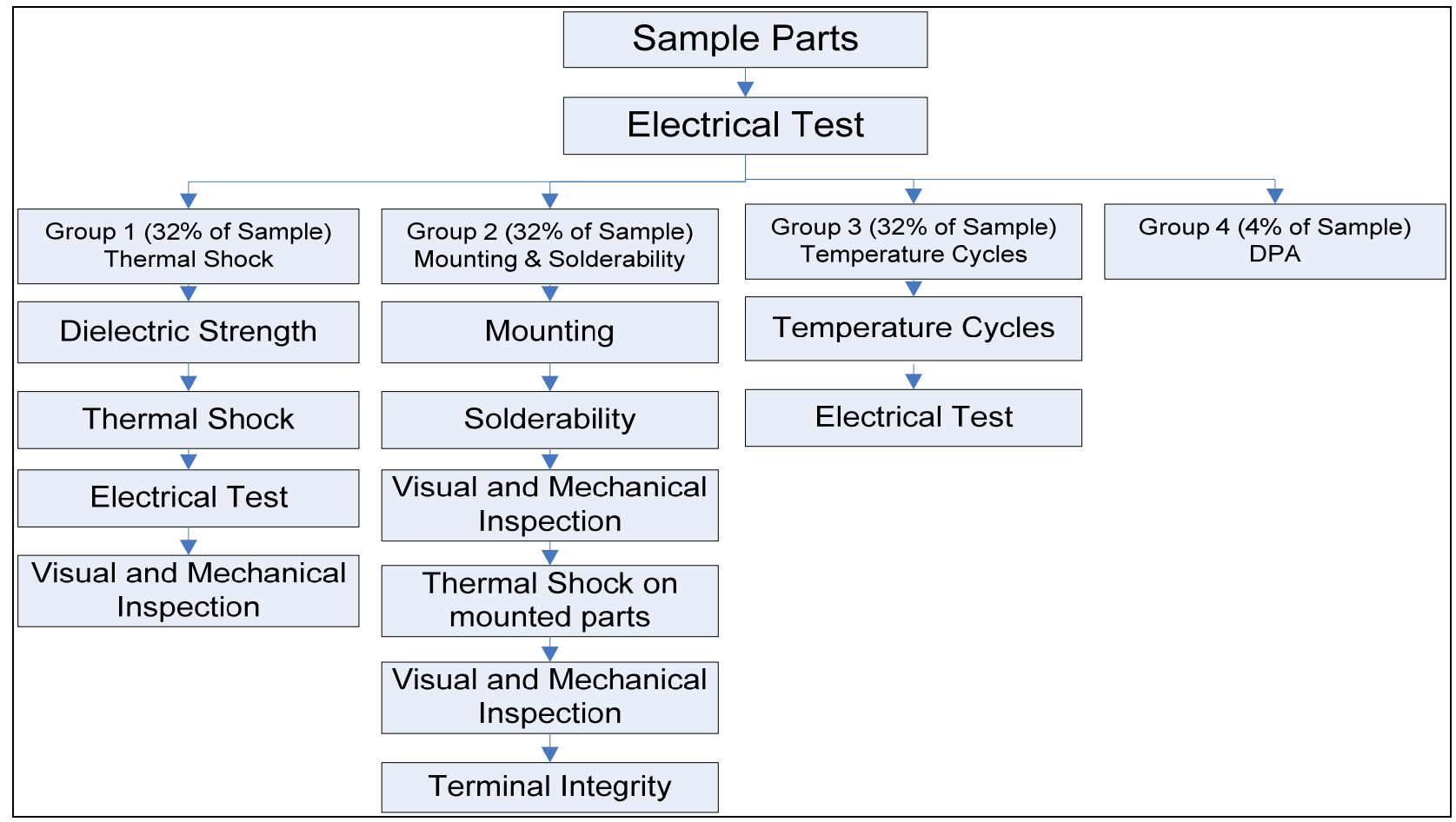

Figure 12. Typical qualification flow for inductors

Inductor qualification took two different approaches. For parts purchased from the manufacturer, qualification was performed by the manufacturer. For parts purchased from distribution, qualification was performed by a selected test house. 
Resistor qualification has two separate qualification flows depending on whether the parts were Mil-Spec or non-Mil-Spec. Both flows are noted in the Table 3 below. Mil-Spec resistors were qualified either at KCP or at an outside test house specializing in Mil-Spec testing. Non-MilSpec resistors were qualified at an outside test house specializing in testing plastic encapsulated parts.

Table 3. Typical resistor qualification flows

\begin{tabular}{|c|c|}
\hline MIL-SPEC RESISTORS & NON-MIL-SPEC RESISTORS \\
\hline Sample parts & Sample parts \\
\hline Electrical testing & Temperature shock (100 cycles) \\
\hline DPA & Electrical testing \\
\hline & DPA \\
\hline & Solderability \\
\hline & Moisture resistance \\
\hline & Marking permanence \\
\hline
\end{tabular}

Capacitor qualification was primarily done by family. For some families, added tests (i.e., surge) are performed by the manufacturer. Capacitors were tested at KCP, and the tests include sample electrical, DPA, and solderability. Most capacitors were Mil-Spec or high reliability and fell into this category of testing.

\section{Development of Outside Test Services}

Development of outside test services for semiconductor devices became necessary due to limited existing equipment available at KCP for testing COTS plastic (PEMs) parts. PEMs require different environmental and mechanical tests that necessitate new equipment if tested for acceptance and qualification at KCP. PEMs packages come in different package sizes, typically much smaller, than the hermetic parts tested for prior programs and would require that new software and hardware be procured for testing. A cost avoidance in capital investment alone was documented at approximately $\$ 6$ million by moving the testing to an outside test facility.

The timeline for researching, piloting, and selecting an outside test house began in 1996. Due to the age of the equipment in KCP receiving inspection, the capital investment necessary to obtain new equipment and the existing initiatives to reduce the KCP footprint, the work to develop an outside test house started prior to the beginning of the Stockpile Life Extension Programs (SLEP's). Work prior to 2000 involved companies with experience in testing hermetic devices. When work with COTS PEMs began in 2000, the focus went to companies with experience in plastic part qualifications. The objective became to find a proven outside test source capable of performing the necessary acceptance, qualification, and reliability assessments of commercial electronic parts. 
The steps for selecting a test house included:

- Research potential outside test house candidates

- PQR-1040 Test House Quality Program released

- Engineering capability studies performed at three potential houses

- PQR-1040 performed

- Pilot project for hermetic parts

- PQR-1040 performed at two new houses

- PQR-1040 performed at three COTS experienced test houses

- Designated Calibration Source (DCS) evaluation at three COTS houses

- Pilot project \#1 for COTS Parts at three COTS houses

The goal for selecting an outside test house was to find a contractor who could manage all test services. No one contractor can do all the testing required, so there would be some tests subcontracted by the selected outside test house. After the initial research, three test service contractors were identified.

The three potential test service contractors were all established as PQR 1040 approved and DCS (calibration) approved. All three test houses were ISO certified and DSCC (Defense Supply Center Columbus) lab process approved. Each test house had greater than 20 years of component test experience in performing qualifications for both military and non-military customers.

KCP formed a team to develop a Scope of Work. The Scope of Work addressed the requirements $\mathrm{KCP}$ expected the test house to meet and the deliverables to be obtained. The outline of the Scope of Work is included in Appendix B.

In order to assess each test house, evaluation criteria were established. The evaluation was divided into two sections, technical merit and pricing. For the technical merit, the test house was evaluated for response to the Scope of Work, performance on the first pilot project, company experience, management and staff, the test house' presentation of the proposal and test house references. For pricing, a list of parts expected to be qualified was included as an appendix to the Scope of Work. Each test house provided pricing based on part datasheets and a suite of qualification tests documented in the SS1A2945. The breakout for awarding the contract was $70 \%$ for the technical evaluation and $30 \%$ pricing. The technical merit factors are listed in Appendix C.

The cost/price factors were rated based on lowest price with other proposals receiving points in a ratio to the lowest price. The total evaluation score was based on 1000 possible points. The KCP Buyer assessed the completeness and compliance to the content and format set forth in the solicitation. The steps for selecting and awarding the contract was as follows:

- Scope of Work/ Request for Proposal (RFP)

- Review RFP with NNSA

- Presentation of RFP to test houses

- Presentation of proposals by test houses

- Evaluation of proposals

- Review proposals and evaluation with NNSA

- Award contract to selected test house 
The selected test house was awarded the master order agreement. Individual part releases were placed through Ariba, with orders set up by selecting from a catalog of test legs (HAST, e.g.). The test house selected had the following key attributes:

- Better equipment capability

- Better test engineering staff

- Better project planning, scheduling, and status reporting

- Stronger subcontractor support

- Stronger references provided

- A more valued cost provider across all semiconductor commodities

- Best performer in pilots

- Pilot \#1 used to perform reliability and qualification testing per SS1A2945

- The selected test house was only test house to complete by promise date

Selection of a test house for passive devices was a subset of the selection process for semiconductor devices. For inductors and resistors, the test house selection process included:

- $\quad$ Scope of Work (SOW)/Request for Proposal (RFP)

- $\mathrm{SOW} / \mathrm{RFP}$ to test houses

- Evaluation of proposals

- Award contract

\section{Pilot Project with Test Houses}

A pilot project was implemented to help with selection of an outside test subcontractor and to exercise the qualification process. This project helped to give hands on assessment of the test house capabilities and performance. The test houses participating in the pilot project demonstrated their ability to quote against the proposed qualification process, estimate reasonable deliveries, address scope of work, provide list of subcontractors, work to delivery dates, demonstrate responsiveness to test issues, and show ability to provide up to date test status. Each test house worked on a select group of devices. The pilot helped to demonstrate the qualification process and the test houses ability to provide work instructions, test product and handle failures. 


\section{Test Data Transfer (TDT)}

Test data transfer became vital due to the amount of parts tested and the amount of test data generated. To be able to receive test data and allow for timely reviews, an automated transfer of data was established (Figure 13). A file transfer protocol (FTP) server was set up outside the KCP firewall that would allow for the third party test house to drop data on a daily basis. The files have a structured file naming convention (Figure 14) allowing for grouping and sorting. Once files transferred through the firewall to a drop zone, scripts were set up to import the data to eCIS and provide notifications to SNL Component Engineers and KCP Product and Quality Engineers that data was available for review. This is a very efficient tool for reviewing and tracking all the test data. Component data is available to anyone with an eCIS account and is accessed at http://ecis.kcp.com/.

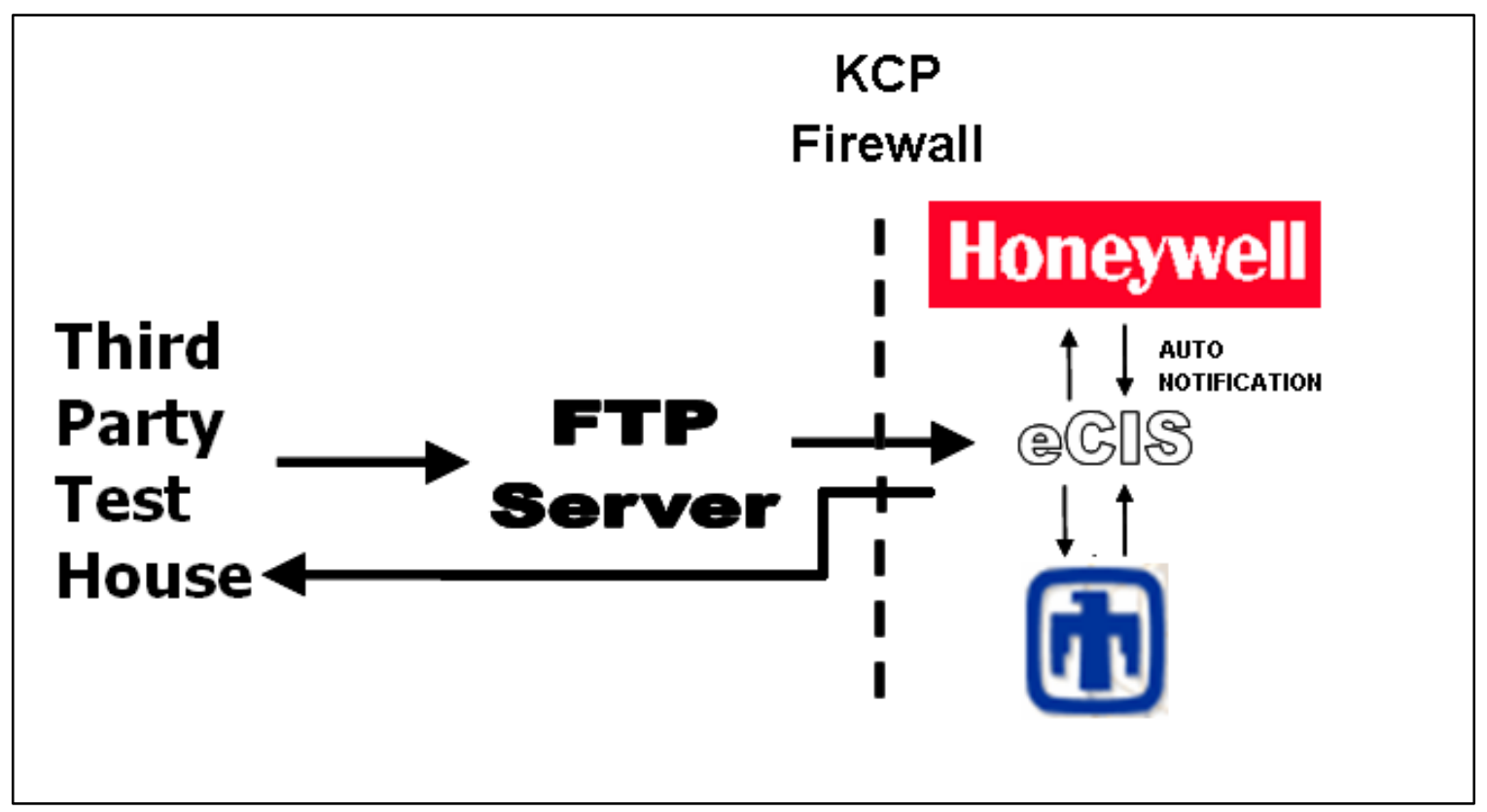

Figure 13. Data transfer from test house to eCIS 
Test Folder for 1A3541-00

\begin{tabular}{|c|}
\hline Name $A$ \\
\hline DDPA \\
\hline ØhAST \\
\hline Ш HTOL \\
\hline DPRECONDITION \\
\hline DSAm \\
\hline ⓉEMPCYCLE \\
\hline УTESTSETUP \\
\hline DTHERMALSHOCK \\
\hline 㐘) Naming_Convention.txt \\
\hline RELIABILITY ASSESSMENT - Discrete.doc \\
\hline 旬]SS1A2945_Rev_A.doc \\
\hline [-흘 Step_Map.txt \\
\hline
\end{tabular}

THERMALSHOCK Subfolder

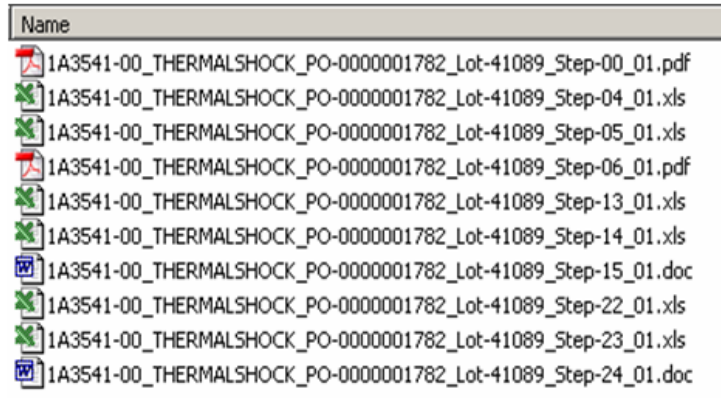

Meanings for underscore delimited file naming convention.

- 1A3541-00 is a 6-Digit NWC Part Number.

- ThermalShock is the type of testing.

- $\quad$ PO-0000001782 is a Honeywell purchase order number for part.

- Lot-41089 is the third part test house lot number.

- $\quad$ Step-00 is the workflow step or test being done.

- 01 is a sequence number for multiple files.

- (Failure) indicates failures in lot.

\section{Figure 14. Data Transfer File Naming Convention}

The eCIS tool for tracking test data was dubbed Test Data Tracker (TDT) and was developed in conjunction with i2 Technologies' services. The eCIS workflow capabilities utilized are essentially a way to control and enforce a series of tasks within a process. The process can't continue until all of the necessary requirements of a specific task are completed. Upon completion of a task, the workflow is promoted to the next task and the associated engineers and/or managers are notified. Workflows have allowed identification and elimination of bottlenecks in the process.

Test Data Tracker Takeaways

- FTP Server is Secure and Robust.

- FTP Server is outside our firewall.

- FTP Server is backed up.

- Outside Test House has full access to read/write files.

- Accessible by KCP and SNL in eCIS.

- Automated error checking of test house filename and files.

- Automated notification when new data has arrived.

- Naming convention pinpoints test flow, part number, and lot information that generated data.

- Purchase Order number can be used to track supplier quality. 


\section{COTS Qualification (QER) Workflow}

A method was needed to determine when all of the qualification testing was complete for a given part, and the documentation had been reviewed, so that the process to generate a QER (Qualification Engineering release) could begin. A new workflow was created in eCIS and the process was rolled out (Figure 15). KCP Purchased Product engineers begin the process by compiling all of the data in eCIS on a lot, reviewing it, and submitting it to the workflow. The information shows up in the SNL component engineer's task in box, where after reviewing and approving it, it is sent to the SNL Quality engineers. The workflow is automatically closed with no further human interaction when the QER is generated, released in Matrix, and metadata is uploaded in eCIS. The component data is available to anyone with an eCIS account. The system provides for tracking of the status of the parts in the closeout phase of the Final Packet Review and QER release processes and is an efficient tool for reviewing and tracking all the test data.

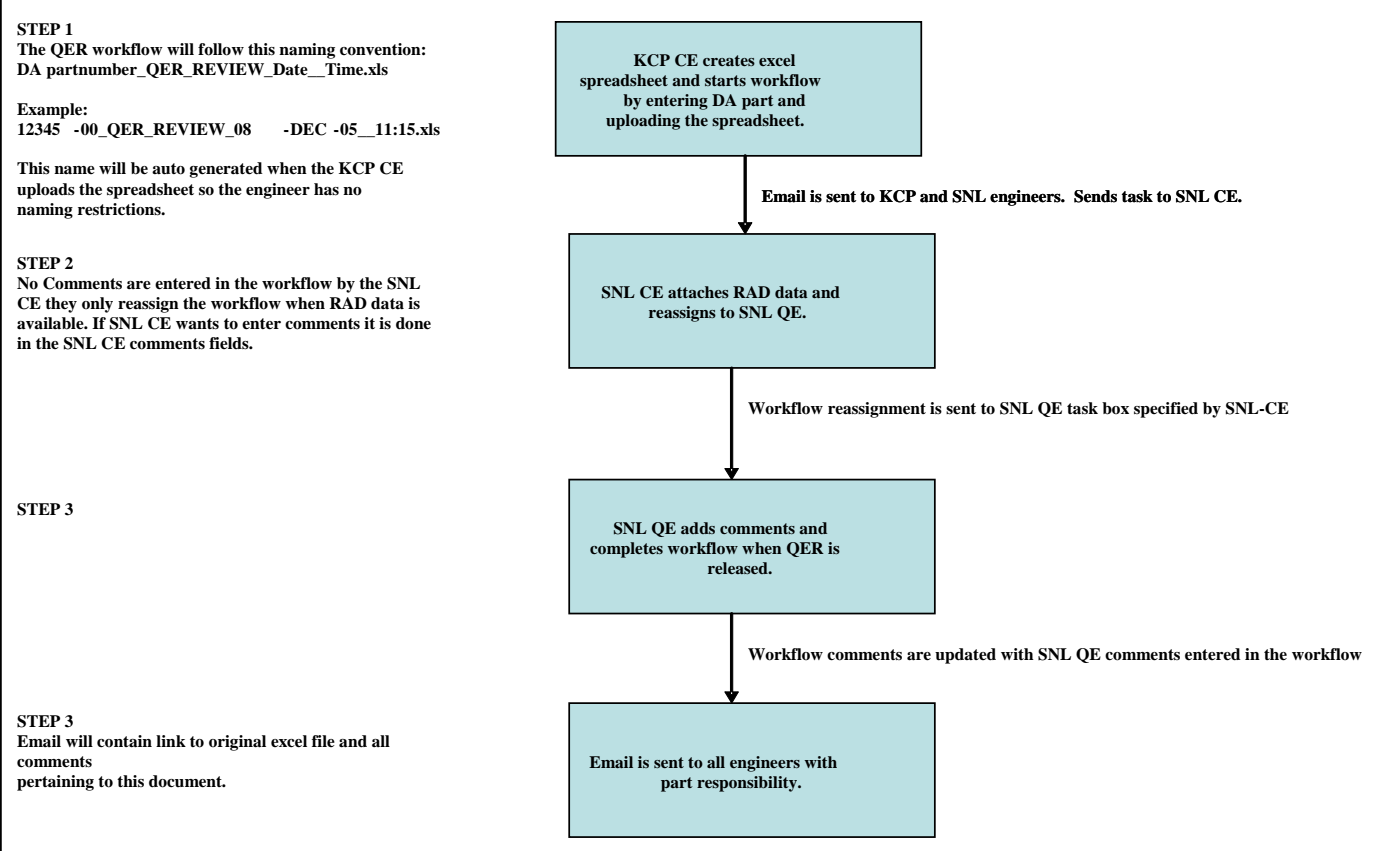

Figure 15. Test Data Tracker QER workflow 


\section{Moisture Sensitivity Handling}

Moisture is one of the biggest concerns with COTS PEMs. PEMs have moisture sensitivity levels (MSL) that indicate how the parts should be stored:

- Level 1: Original factory moisture barrier bags with desiccant and humidity indicator card, reseal as necessary.

- Level 2: Original factory moisture barrier bags with desiccant and humidity indicator card, reseal as necessary.

- Level 3: Sealed moisture barrier bags with desiccant and humidity indicator card, including external caution label.

- Level 4: In addition to Level 3 requirements, maintain exposure time log. Dry nitrogen stores preferred.

SNL performed experiments on the effects of preconditioning on reliability. SNL's testing included MSL 1, 2a, 3, no relative humidity, and bake-outs. The experiments showed that moisture absorption is the key to damage at solder reflow. This supports the need for proper MSL classification and handling.

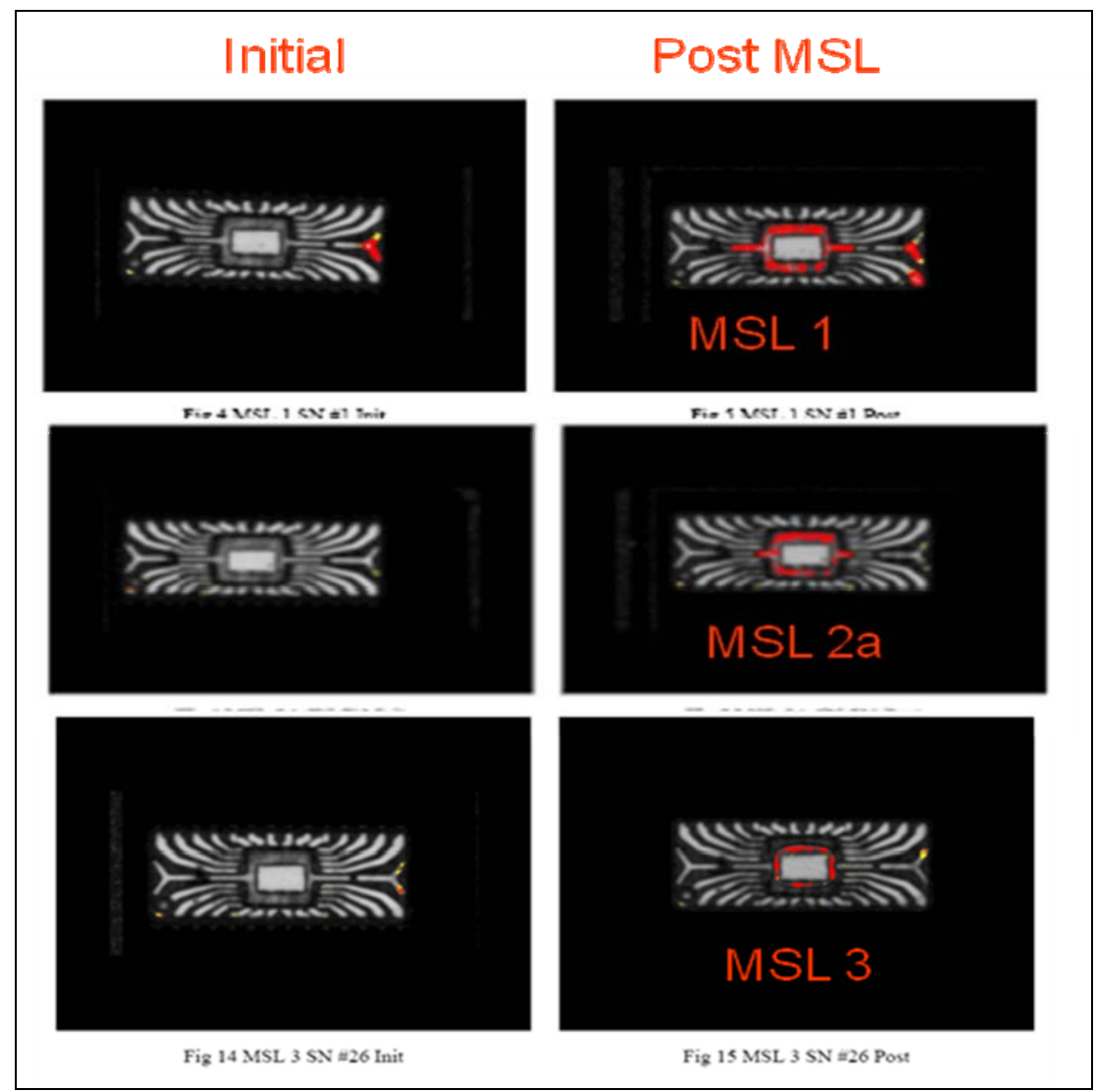

Figure 16. Acoustic images from SNL moisture experiment 
Manufacturer datasheets and SNL development activities for parts used indicated that all parts were MSL 1. Qualification results indicated that parts may not be MSL 1, and indeed, they may be MSL 3 or 4 . This required the next assembly to establish controls to handle MSL 3 parts. A specification was released in the next assembly to implement best handling practices for MSL 3 parts.

During qualification, parts were preconditioned based on the MSL rating. Improper ratings were potentially creating failures at qualification. Failure resolution involved MSL re-classification and the repeat of qualification tests to an adjusted MSL level. To mitigate risks for parts starting qualification late, MSL 3 was assumed.

COTS parts are stored in moisture barrier bags with desiccant per SS1A3023. Each bag has a label indicating the MSL rating for the parts and a barcode label. For parts on reels, an assigned reel number was included on the barcode label. Each reel for a part has a different reel number (Figure 17). Notes were also added in ERP (Figure 18).

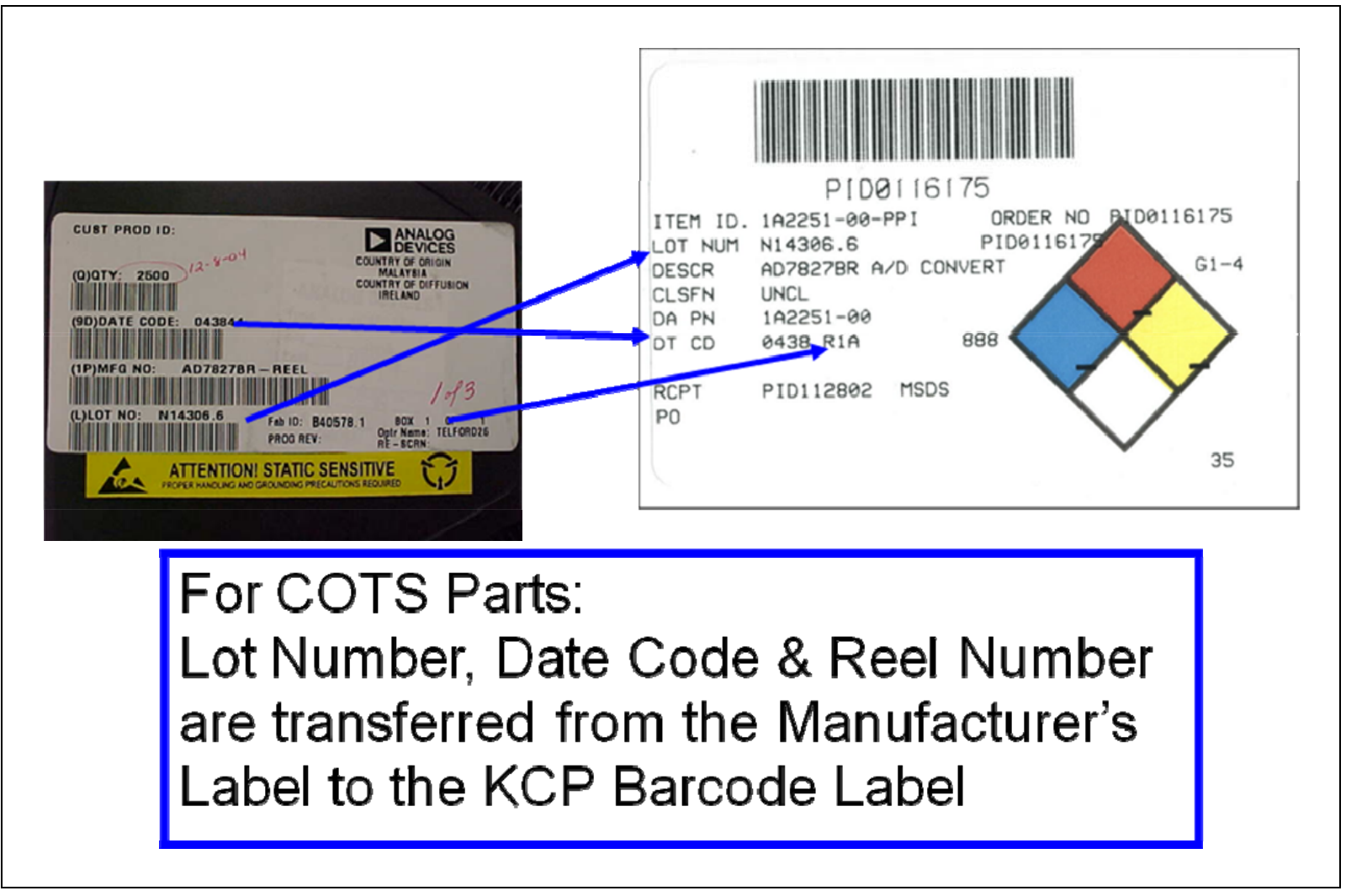

Figure 17. Example of barcode label for COTS part 


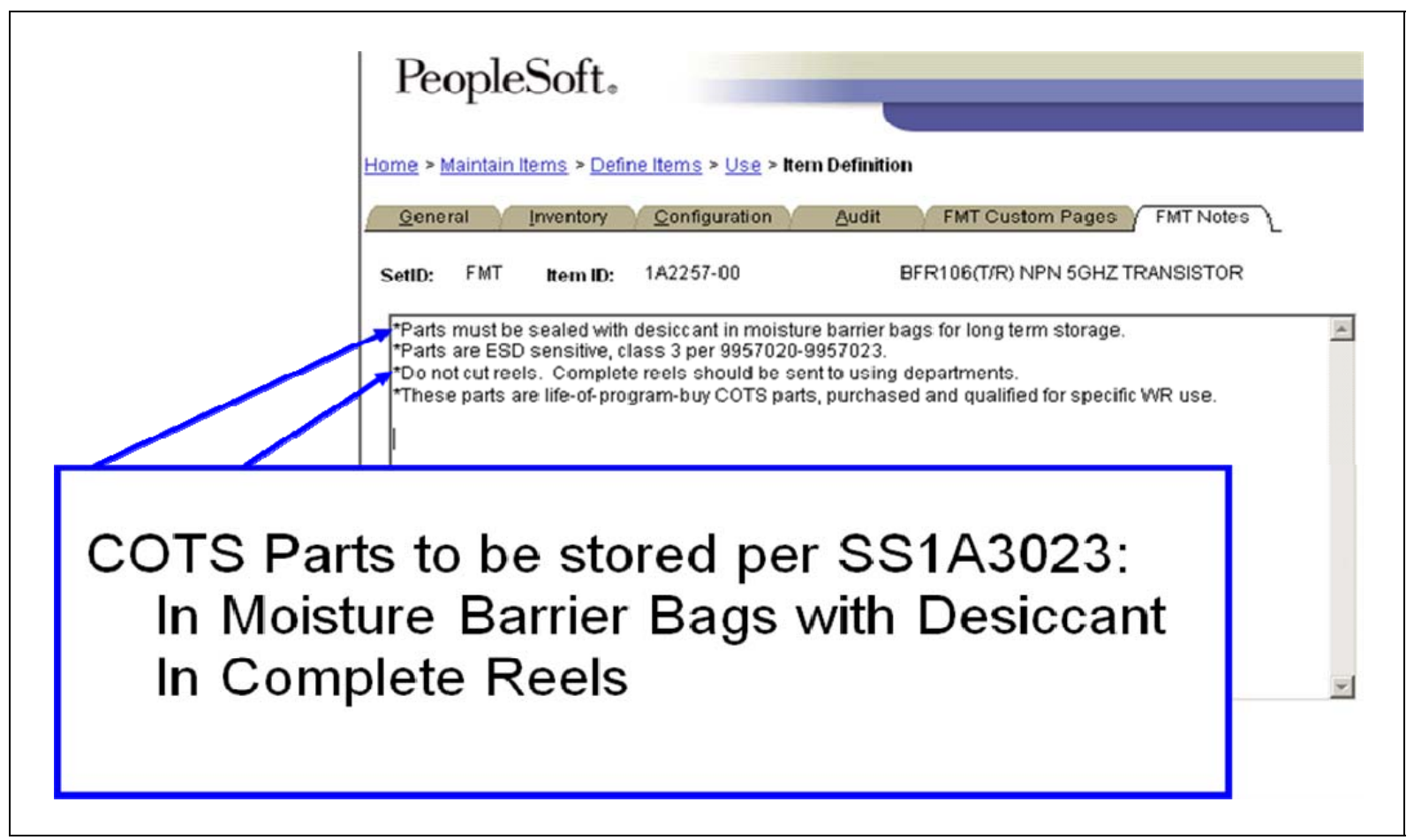

Figure 18. Example of ERP item notes for COTS part

\section{Solderability Issues}

A surface-finish Product Realization Team (PRT) was established with the objective to put in place guidelines and/or best practices to utilize a variety of device lead and printed circuit board (PCB) finishes so as to meet the cost, schedule, and process and reliability requirements. Issues involved pure Tin (Sn) leads, Gold (Au)-Nickel (Ni) leads, Palladium (Pd)-Nickel (Ni) leads, and solderability lifetime while in stores.

\section{$\underline{\text { Pure Tin }(\mathrm{Sn}) \text { Leads }}$}

The issue with Sn leads is Sn whisker growth (Figure 19) which can cause short circuits and particles.

The best mitigation strategy is to avoid using parts with pure Sn leads. 27 parts ( 2 transistors, 25 inductors) were purchased and qualified with pure Sn leads. Studies performed by SNL showed that normal solder will mitigate Sn whisker growth for these parts. SAND report 2005-7805C documents the mitigation strategy evaluations and results. A recommendation memo was issued 2/20/06 (Aragon, Wavrik). 


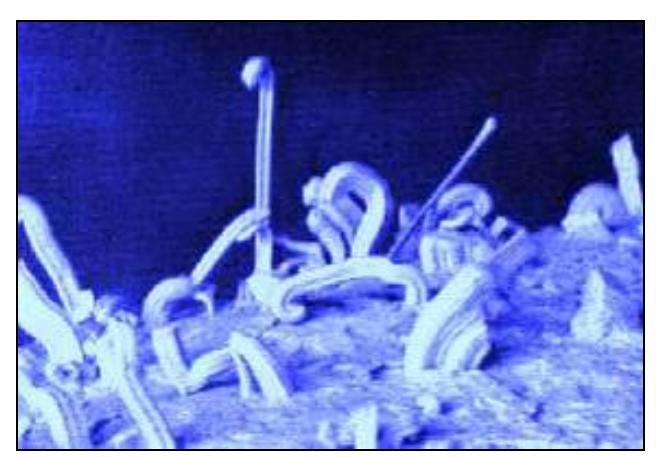

Figure 19. Close-up of tin whiskers

\section{Gold (Au)-Nickel (Ni) Leads}

For parts with gold ( $\mathrm{Au})$ plated leads, an issue occurs when the Au is too thick $(>2.5 \mu \mathrm{m})$. This causes Au embitterment of solder. An issue also occurs if $\mathrm{Au}$ is too thin $(<1.3 \mu \mathrm{m})$ where poor solderability of the $\mathrm{Ni}$ finish results in solderability lifetime issue.

The best mitigation strategy is to purchase parts with Au over Ni between 1.3 and 2.5 microns. However, these are COTS parts with no imposed requirements on the supplier. For parts with $\mathrm{Au}$ plating, parts are dipped prior to assembly at an outside solder dip facility.

\section{$\underline{\text { Palladium (Pd)-Nickel (Ni) Leads }}$}

Issues with Palladium-Nickel (Pd-Ni) leads include solderability of Pd and reliability of retained Pd. There were two parts with Pd-Ni leads. These parts are to be used without solder dip.

\section{$\underline{\text { Solderability Lifetime In Stores }}$}

Issues include storage lifetime durations, storage conditions, and solderability surface finishes. Lead finish and solderability are verified in qualification.

The primary mitigation strategy is to store parts in moisture barrier bags backfilled with Nitrogen $\left(\mathrm{N}_{2}\right)$ and sealed with desiccant. In addition, a 100-piece sample has been pulled from each production lot of material to be used for periodic solderability testing. The solderability samples are sealed in moisture barrier bags, backfilled with $\mathrm{N}_{2}$ and contain desiccant. Solderability intervals will be as defined in the individual product specifications and SS1A3023 and is typically three years.

\section{Examples of COTS Qualification Issues}

During qualification testing, there were 37 first time failures for the 342 COTS devices types tested (summarized in Table 4). The qualification process was established to find parts considered to be weak. The majority of the failures found were due to over specified requirements or to over stress condition following preconditioning. 
Table 4. Summary of COTS Qualification Issues

\begin{tabular}{|c|c|c|c|}
\hline Quantity & Example Failure Analysis & Resolution & Lessons Learned \\
\hline 22 & $\begin{array}{l}\text { Inductors had overspecified lead } \\
\text { pull strength }\end{array}$ & $\begin{array}{l}\text { Minor limit } \\
\text { changes }\end{array}$ & $\begin{array}{l}\text { Need to fully understand } \\
\text { part requirements. }\end{array}$ \\
\hline 6 & $\begin{array}{l}\text { Part failed stress testing after } \\
\text { MSL } 1 \text { preconditioning }\end{array}$ & $\begin{array}{l}\text { Qualified and } \\
\text { handle parts at } \\
\text { higher moisture } \\
\text { sensitivity level }\end{array}$ & $\begin{array}{l}\text { Preconditioning affects } \\
\text { reliability. } \\
\text { Mfg. MSL rating is based } \\
\text { on commercial reliability } \\
\text { requirements, not WR } \\
\text { requirements. } \\
\text { COTS paradigm impacts } \\
\text { next assembly techniques }\end{array}$ \\
\hline 5 & $\begin{array}{l}130^{\circ} \mathrm{C} / 85 \% \mathrm{RH} \text { HAST } \\
\text { overstressed eutectic die attach }\end{array}$ & $\begin{array}{l}\text { Qualified using } \\
\text { lower } \\
\text { acceleration, } \\
\text { longer time tests }\end{array}$ & $\begin{array}{l}\text { Need to fully understand } \\
\text { part construction relative } \\
\text { to stress testing. }\end{array}$ \\
\hline 4 & True failures & Acquired new lots & $\begin{array}{l}\text { COTS have lot-to-lot } \\
\text { variability. } \\
\text { Process was successful in } \\
\text { identifying weak parts. }\end{array}$ \\
\hline
\end{tabular}

Not all test issues were a result of failures during qualification. Lot to lot variation is one of the risks when buying COTS parts. One example was a bipolar transistor which showed 2 examples of how COTS parts change over a 2 to 3 year period of time. After initial electrical testing on the LOPB production material, there was a noted difference in the S-parameters that affected one out of four socket locations in the next assembly. This difference was identified on four of the six reels of material and showed as a bi-modal distribution.

Initial investigation noted that the LOPB material was physically different from the characterization material. The LOPB material had die mounted on top of the die paddle (Figure 20) while the characterization material had die mounted on the bottom of the die paddle (Figure 21). Though this difference caused some initial concerns, this did not end up being the cause for the bi-modal distribution seen on the LOPB material. The die paddle/die placement was a change in the manufacturer's process between the characterization build and the LOPB build but did not affect the qualification of the material.

Since each reel is sampled during qualification, identification could be made to identify which reels would work for the more sensitive application. A new part number was created for the three less sensitive socket positions, and the lot was split into two groups. Qualifications were performed on each part number. No cause was identified for the difference in S-parameters, but something besides the die to paddle mounting changed over the period when the material was built. 


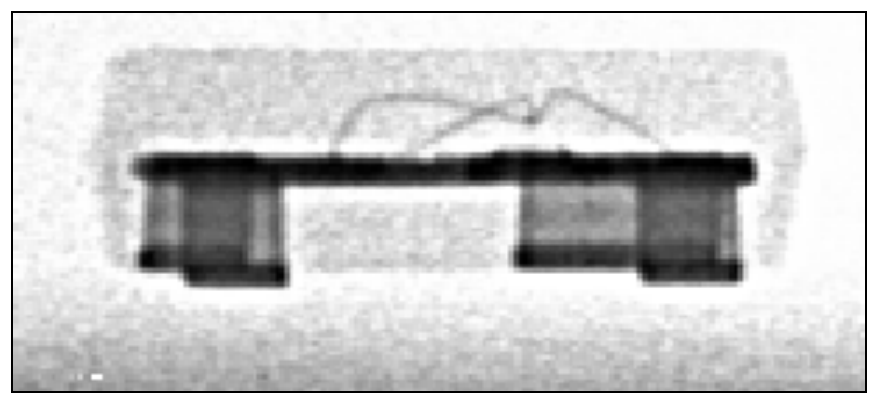

Figure 20. X-Ray of Bipolar Transistor LOPB Production Part

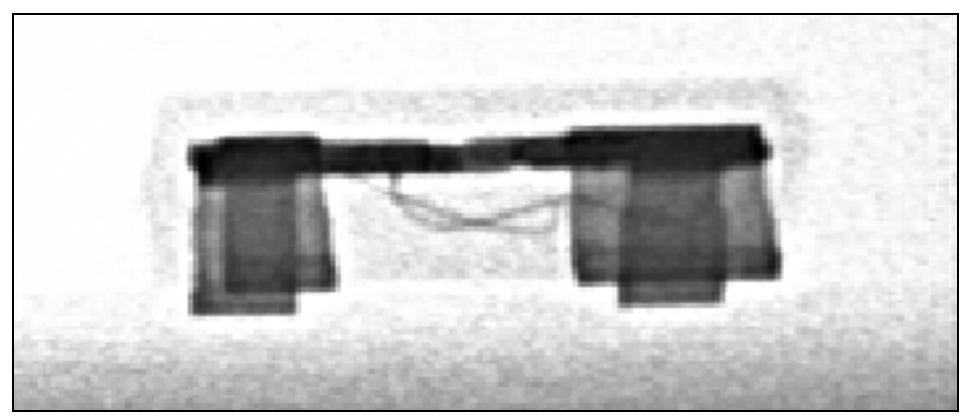

Figure 21. X-Ray of Bipolar Transistor Characterization Part

\section{Enterprise Component Information System (eCIS)}

eCIS is available throughout the Nuclear Weapons Complex (NWC) via the ExtraNet. The software is the Product Sourcing Module of the SRM (Supplier Relationship Management) Suite from i2 Technologies, and the system includes a subscription to reference data from Information Handling Services (IHS) for over 25 Million electronic and electromechanical commercial and military parts. With the capabilities added to the system through this project, detailed elsewhere, eCIS now provides decision support, parts list/BOM (Bill of Material) analysis, editing, tracking, workflows, reporting, and history/legacy information for purchased parts in the format the user needs. Manufacturer reference, company technical, company business, and design data is integrated from multiple KCP and SNLA systems (see Figures 22 and 23). KCP \& SNL enter data into the system. 


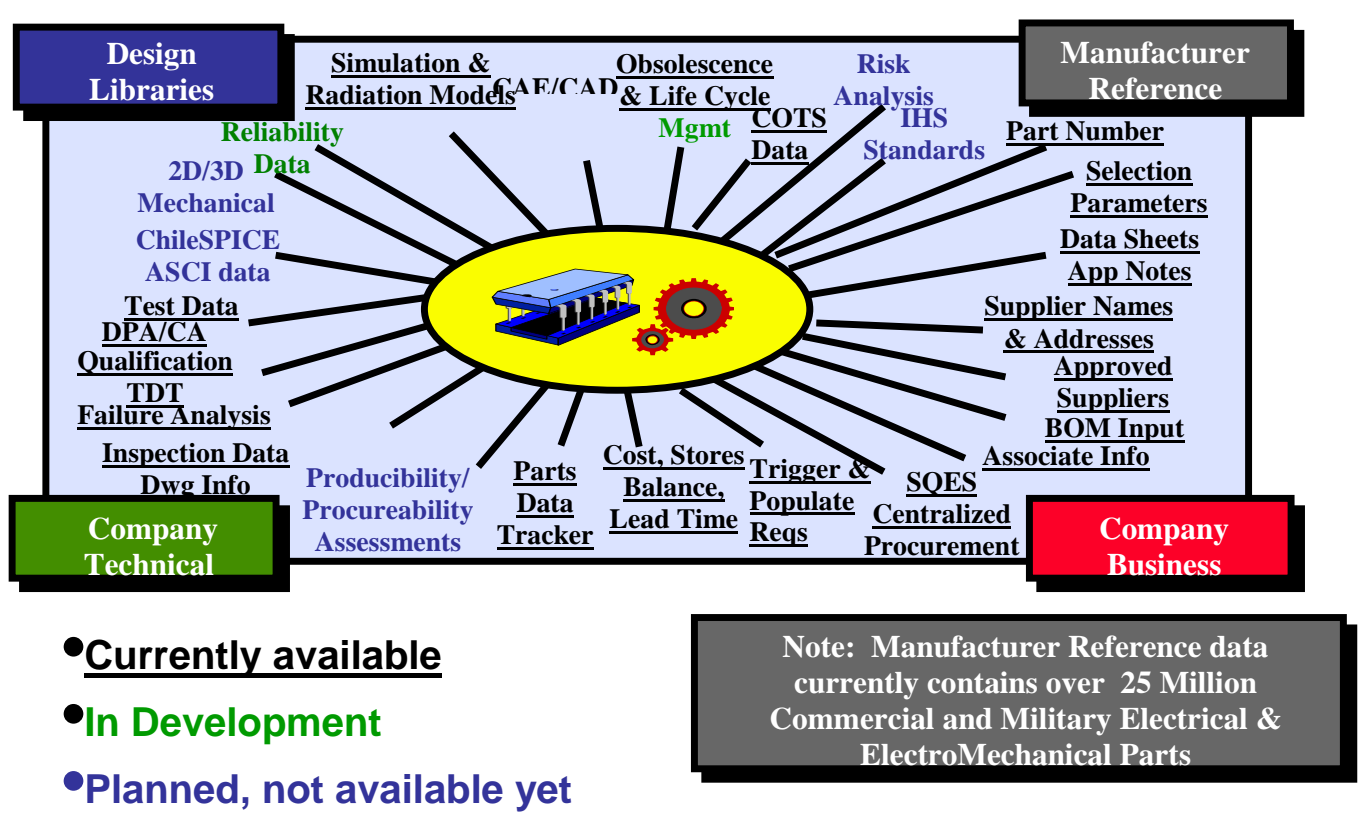

Figure 22. eCIS Data

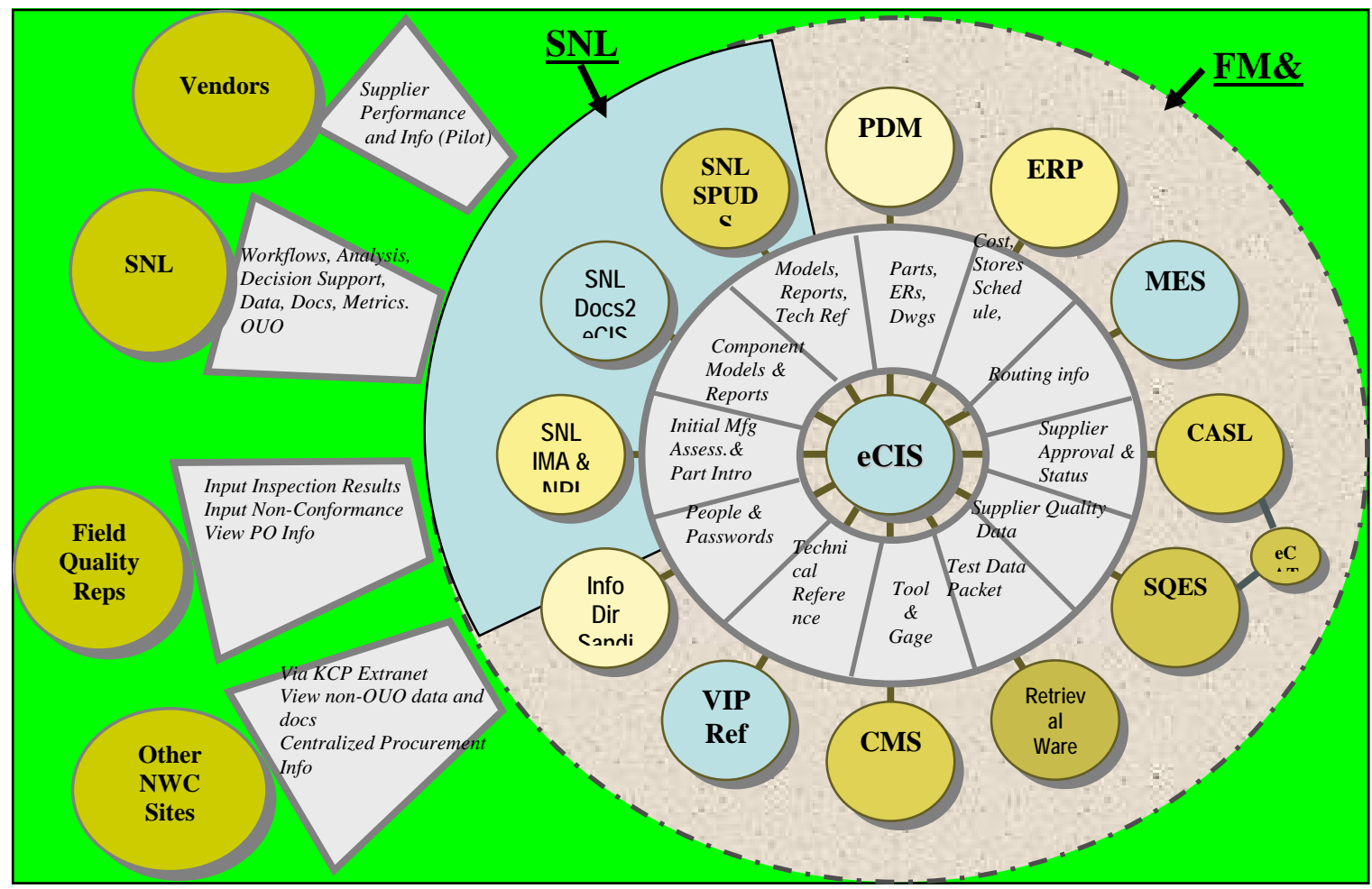

Figure 23. eCIS Data Sources and Inputs 
Components are the building blocks for weapon systems. Large numbers of electronic devices are in weapons systems. Efficient design and production requires good decisions on component selection early in the product realization process. Product costs are committed in the early phases as design decisions are made, even though they are not incurred until the late stages of the product life cycle. Rapid, low-cost design and production of complex systems requires information for managing tradeoffs. The best decisions are made when not only design and technical data, but also business data and manufacturing data are included in the process.

Overall costs of the system are reduced if the selected parts are producible and procurable. eCIS provided the data for this decision support, bringing in business data such as flow time, cost, part quality history, supplier history and qualifications, etc.

eCIS provides virtual corporation capabilities required for a transformed complex.

1. Improves responsiveness \& competitiveness by:

- reducing cycle time for component selection

- reducing time for component qualification

- maximizing component and component data reuse

- managing use of COTS parts

- facilitating concurrent engineering

- using previous analysis for future projects.

2. Enables cost reduction by:

- guiding selection of the right suppliers - leaving fewer suppliers to qualify \& maintain

- choosing parts that are procurable - so that additional costs are not incurred by having to re-design

- driving designs for manufacturability.

3. Improves quality by providing feedback loops for the design process.

4. Provides efficient supply chain management by providing:

- forward looking tools (leading versus lagging indicators)

- rapid alternate parts selection and comparison

- proactive management of lifecycle \& obsolescence

- supplier quality management and feedback

- reuse of standardized CAD library information.

All NWC sites can benefit from one site's experience.

Features in eCIS that enable the benefits just described include: finding, evaluating, and selecting the best parts and suppliers; finding and reusing existing parts and suppliers; being able to find all of the data about a part though eCIS cross-referenced to models, reports, commercial part data, test results, procurement status, etc from multiple systems. Additional features are notifications of alerts on parts and/or part data; communication/notification of alerts and problems; enforced part workflows; change notices and discontinue notices by manufacturers. 


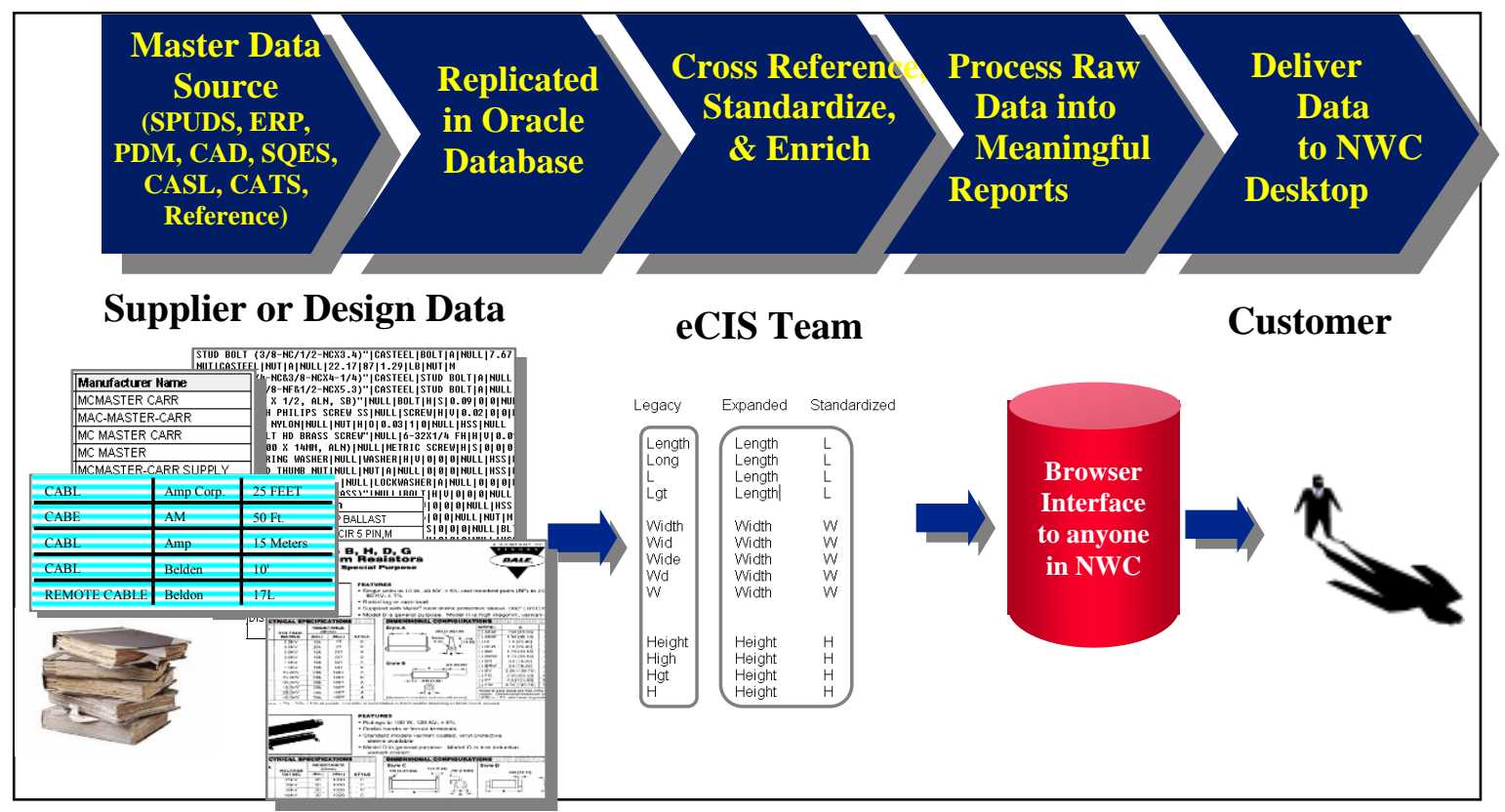

Figure 24. Supplier or Design Data to Customer

\section{Solderability Tracking}

Periodic solderability testing of Life of Program Buy (LoPB) parts needs to ensure that the parts remain solderable. The metamodel for the data about those parts was created in eCIS to allow tracking of ongoing solderability testing based on solderability item and group. The system was set up so that items could be grouped, and if one item passes solderability testing, then the whole group is acceptable for that period of time. If test item fails, a larger sampling of the group will be selected and tested to verify solderability. Grouping reduces the number of solderability tests and samples needed by selecting a representative sample from a group of similar products based on manufacturer, manufacturer location, part type, package type, and date code. The initial input data loaded into eCIS includes all current solderability items, groups. and supporting information. When periodic solderability testing is completed the results will be fed into eCIS providing traceability back to the solderability group and item. Automatic email notifications will be sent out when periodic solderability testing of Life of Program Buy (LoPB) lot is needed using the planned test dates associated with each group. 


\section{Parts Data Tracker (PDT)}

Tracking of COTS parts was achieved through the use of manual inputs in Excel spreadsheets. Data was gathered manually from multiple information systems to update spreadsheets for over 25 data elements for each part, as well as some common data (see Figure 25). Each data element typically has a start date, due date, and actual date. In order to provide visibility for preproduction need dates and support documentation from the project plans and monitor status of purchased parts supporting project plan deliverables, Parts Data Tracker (PDT) functionality was developed in eCIS. This capability would automate the collection of data needed, provide a database repository of COTS tracking information so that all users would have access to the same data, minimize manual data entry, and auto-plan start dates and dues dates based on PPI (Process Prove-In) due date. This capability was developed in conjunction with i2 Technologies' services.

ERP (Enterprise Resource Planning) Item information is used to synchronize data with ERP. If the ERP Item value entered does not match the ERP Item value that gets set up in ERP, updated data from ERP will not be available. An ERP Item description that is manually entered in eCIS will be overwritten by the ERP sync process once Item Setup is complete. The ERP Item value is used to search the Purchased Part class to determine Quality Engineer, Product Engineer, \& Buyer. A configuration was created that allows viewing of COTS ERP information and Purchased Part ERP information.

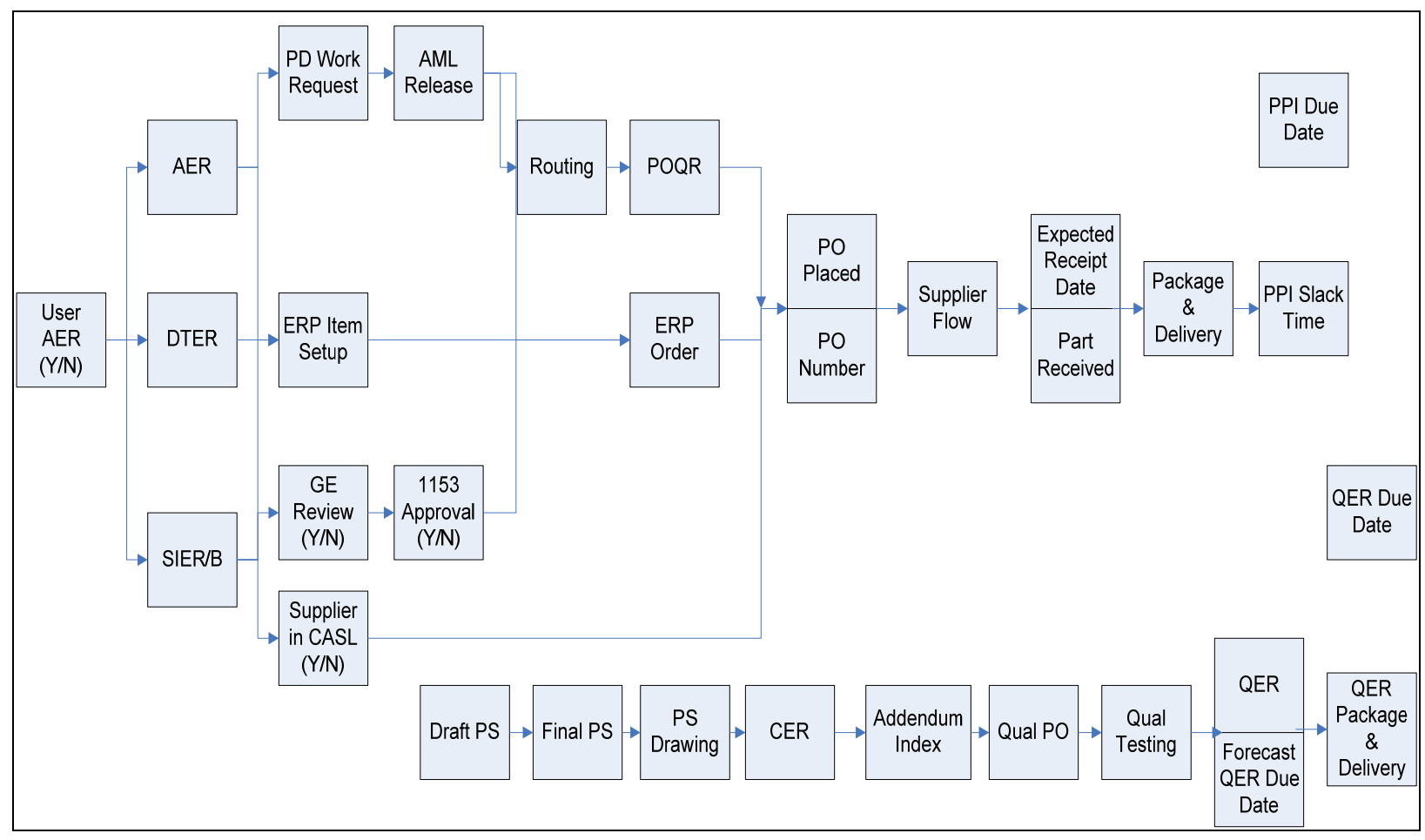

Figure 25. COTS Data Process Map 
Mechanisms used the PDT capabilities developed to allow an unclassified list of purchased parts that was maintained by program management to be managed within eCIS. It has all of the eCIS information for the parts as well as information retrieved from Matrix, ERP and PeopleSoft. Prior to eCIS, they used an Excel spreadsheet (such as the weapon playbook), shared by several associates, to track their parts and had to manually pull the required information from other systems. The new tools ensure all of the reliability, security and availability of an Enterprise Database Tool. The scope is this project was limited to certain weapon program mechanical purchased parts, including weld samples.

Parts Data Tracker for the Mechanisms resulted in a cost savings of $\$ 53 \mathrm{~K}$. Benefits gained from using eCIS included visibility of the same data to both KCP and SNLA customers, improved accuracy of data being tracked, and data automatically updated every 24 hours. Less time was spent by purchasing and program management associates inputting data, more than one user could make changes at the same time, and a complete listing of purchased parts was available by utilizing the cross reference information.

\section{Bill of Material (BOM) Management}

Previous activities for this project integrated part design, business and technical data from multiple systems at KCP and SNL. Building on that foundation, BOM/Parts Lists management capabilities were developed and deployed.

The need for bottom-up planning for development had been identified during the Procurement Value Stream conducted in June 2006 for the TestWorks NNR Campaign. Designs are received from the bottom up, but currently, the planning system plans from the top down.For the development phase of a project, the infrastructure was created to load BOMs into eCIS, provide the data to analyze the assembly for component buy decisions, and send the data to ERP which then sends a requisition to the buyer for procurement of the part(s) (see Figure 26). Additional capabilities include: easy searching via shortcuts and forms; cross-referencing between Design Agency part numbers, commercial or military part numbers, ERP Item, and Matrix Drawing numbers; parts data tracking; and part analysis such as Life cycle analysis (availability - years to end of life) to mitigate obsolescence issues; procureability analysis; part cost analysis; and, part history/quality analysis.

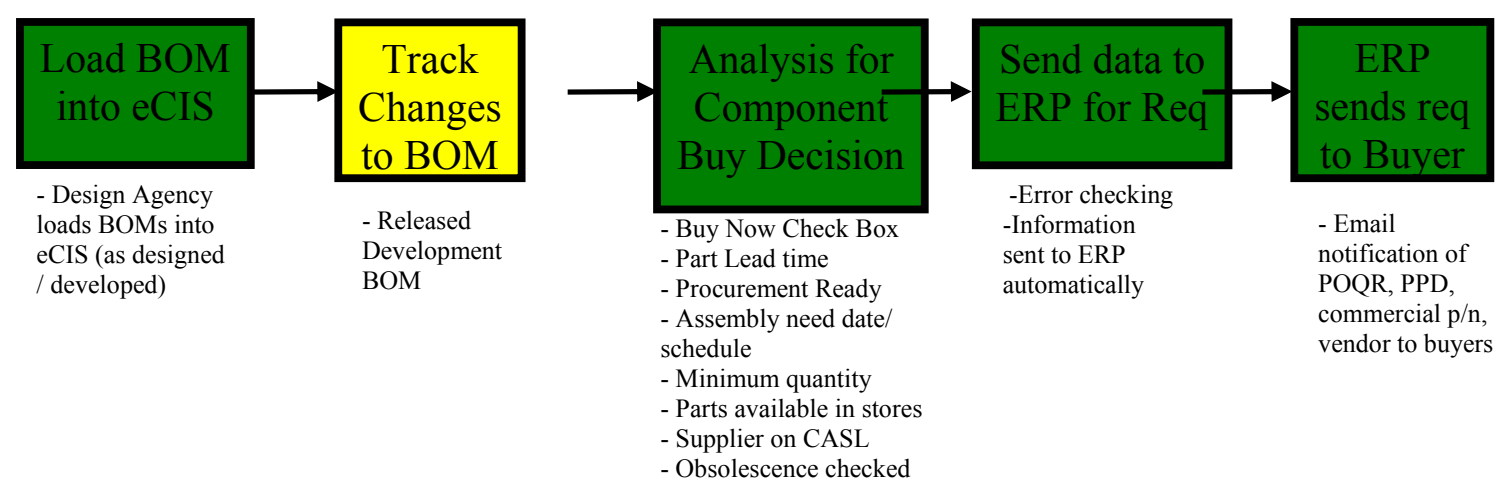

Figure 26. BOM to Requisition Process 
The W88JTA2R pilot system has realized the following results:

- BOM/Part Analysis Results - identified \& remediated the following:

- 44 Parts with estimated Flow times that would not support PPI

- 30 Parts needing Item Setup

- 104 Parts without Buyers

- 1 Part with multiple MSRs (what is this?), saved $\$ 90,000$ in part costs

- 4 Parts - Obsolete; 1 Part - Declining Availability

- 159 Parts needing Cross References

- Improved parts total cost estimating

The system also made it easier to track potential stopping points and provided a single location for BOM information before production.

Old Process: 47 days / project

\begin{tabular}{|c|c|c|c|c|c|c|c|c|}
\hline \multicolumn{9}{|c|}{ Manual Process } \\
\hline $\begin{array}{c}\text { BOM } \\
\text { Created } \\
\text { in Excel } \\
\text { or Access }\end{array}$ & $\begin{array}{c}\text { Parts } \\
\text { Updated } \\
\text { as } \\
\text { Change }\end{array}$ & $\begin{array}{c}\text { Periodic } \\
\text { Lookup } \\
\text { of ERP/ } \\
\text { Matrix Info }\end{array}$ & $\begin{array}{c}\text { Create } \\
\text { Dummy } \\
\text { ME Deck } \\
\text { in ERP }\end{array}$ & $\begin{array}{c}\text { Input } \\
\text { Schedules }\end{array}$ & $\begin{array}{l}\text { Demand } \\
\text { Generated }\end{array}$ & $\begin{array}{l}\text { Periodic } \\
\text { Calls to } \\
\text { Find } \\
\text { Problems }\end{array}$ & $\begin{array}{l}\text { Repeat } \\
\text { for } \\
\text { PPI }\end{array}$ & $\begin{array}{c}\text { Repeat } \\
\text { for } \\
\text { Production }\end{array}$ \\
\hline
\end{tabular}
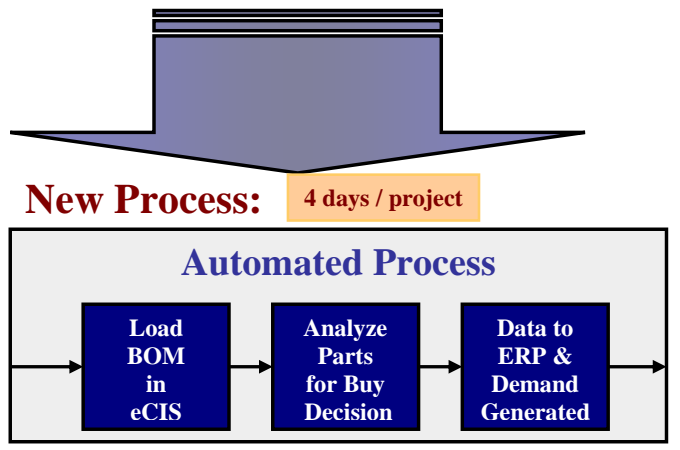

Figure 27. BOM Old versus New Process

Issues with the "out of the box" software were resolved so that redlining and revision/promotion capabilities can be used on new projects. A training PowerPoint and video were created for the BOM input, redlining, and revisions. The introduction contains a video of the W88JTA2R manager discussing how this system and process saved the W88 four to five months (see Figure 27). The training included how to create projects and assign project members.

In eCIS, BOMs, assemblies, and/or parts lists are grouped together in Projects. BOM access permissions are controlled at the project level. Within a project, different members may have different privileges. Members of a project can share information within the project. The project must be defined before any solution activity can be performed. The creator of the project is identified as a project manager. The project manager can add members to the project with different privileges. It is a bottom up system, requiring the lowest level parts and assemblies be defined in the system before the assemblies above it can be input. Parts can be added from internal items or other projects. 
Redlining capabilities allow proposed BOM/assembly/part list development changes to be tracked as "redlines" (edits are shown in red). This redline version is submitted for review, and if accepted will be "promoted" to the next revision of the BOM/assembly/part list. Each PRT team can determine who needs to review and accept the proposed changes before they are accepted. Previous revisions are maintained in the system as read-only BOMs for reference as needed by the team members.

\section{Quad Site CAD Library Part System}

The Quad Site (KCP, SNLA, SNLL, LANL) Electrical CAD (Computer Aided Design) Library team needed a workflow for library part creation. This workflow was to support streamlining of WG2005 PCB (printed circuit board) process in order to decrease cycle times, decrease the total cost of designing and processing PCB's, and eliminate duplication of effort between sites. The previous process used was an excel spreadsheet to keep track of new requests for library parts. The system allowed duplicate, and potentially conflicting, library parts to be generated for the centralized library by librarians from different sites. Also, there was no tracking of the status of the part creation. Furthermore, the library was not easily searchable for existing library parts. SNL started a project and hired a programmer to create an application that would solve these issues, but was unsuccessful in completing the project.

The new process uses a web page, with error checking to reduce input errors, that is available to anyone in the NWC to request a new library part. The new process is shown in Figure 28. Tracking and metrics (similar to PDT) for library and board design improve feedback for Quad Site library management and for KCP EDMA (Electronic Design and Manufacturing Automation) management.

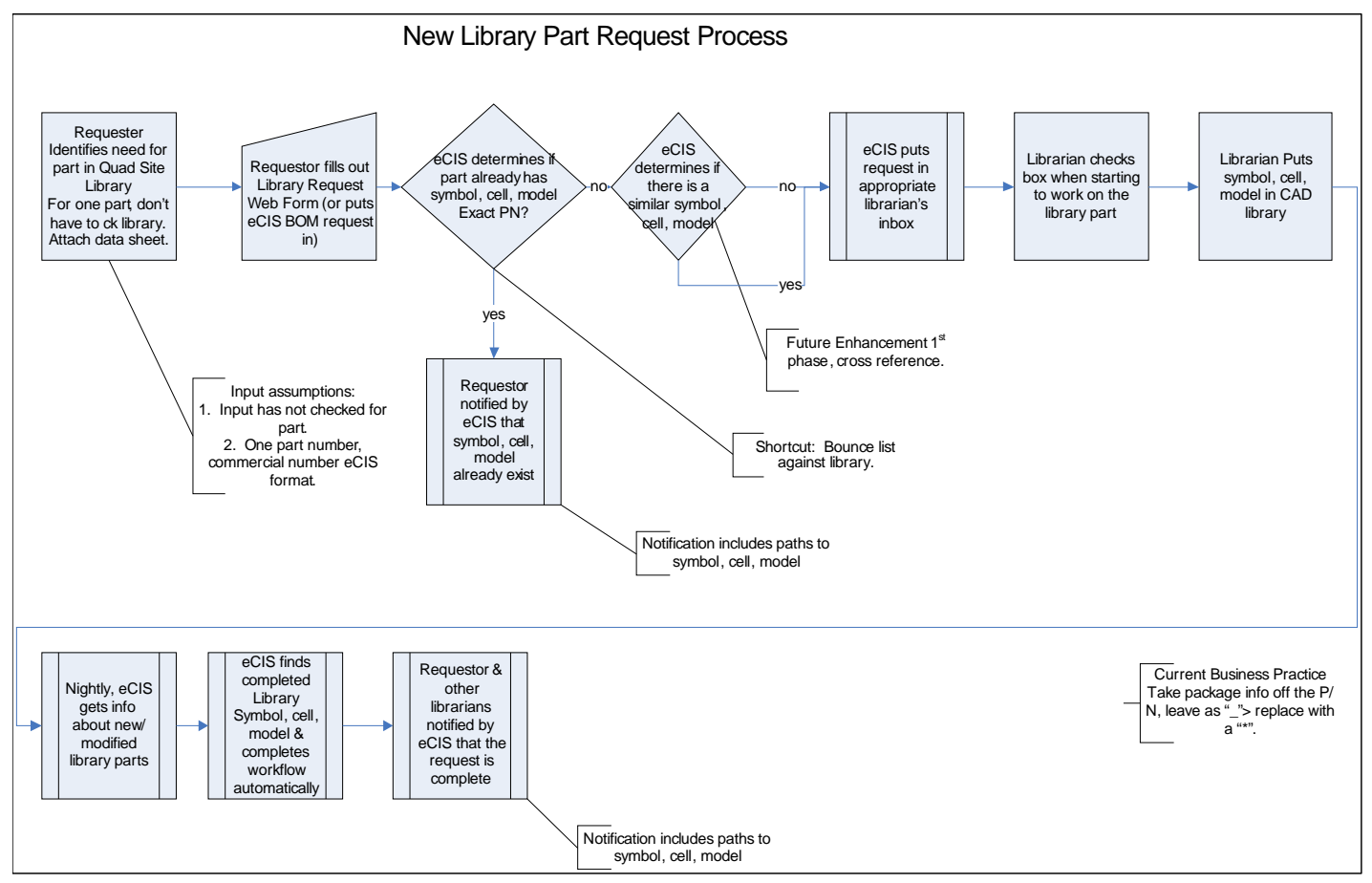

Figure 28. Workflow for Library Part Creation 


\section{Classified eCIS at SNL}

As SNL used eCIS and understood the value of it's analysis capabilities, they realized that a Classified eCIS was needed to take full advantage of the available tools. A Classified eCIS would allow full BOMs to be analyzed for quality, costs, obsolescence prediction, lifecycle, alternate parts (upgrade, downgrade, equivalent) and suppliers. Present methods of association of component data with an integrated parts list had problems. A classified system would allow linking that supports concurrent engineering, association of classified electrical models to parts, facilitate storage and retrieval of classified development circuits and subcircuits, and enable an integrated view of the entire weapon system.

All of the data and capabilities in the unclassified eCIS system at KCP were reviewed to determine which data needed to be sent to SNL. The first phase was to migrate to SRM. This was done to provide functionality necessary for SNL to deploy classified. It required major datamodel restructuring which in-turn required rewriting most of the existing custom applications to accommodate the new structure. The rewrite of the software for the SRM Migration allowed separation of the TDT and PDT into 2 distinct programs. They had been developed as a single application per the original software specification. The separation will allow us to leverage the PDT functionality in future projects.

The second phase of the project was to develop a methodology and process to provide the unclassified data, structure, custom functions, triggers, etc., on a periodic basis to SNL. The first step was to provide a snapshot of the current system to SNL. Then SNL moved it to their classified server. A couple of methods for sending incremental updates were tried resulting in an automated process using triggers within eCIS to identify data that has been added, changed, or deleted. This data is then bundled up in the software's loading format and sent to SNL. Opportunities for data integrity issues were resolved by utilizing the systems error checking in place at SNL.

\section{Level 2 Milestone}

The level 2 milestone exit criteria, to enable eCIS to be deployed on a classified system at SNL, was met. eCIS is a single information system that provides design and production electrical engineers the ability to evaluate and choose components. They make lifecycle choices and analyze BOMs/Parts Lists based on data, from multiple information systems, including commercial availability, supplier performance and component quality. Additional data sources include Quad Site cad library data, which enabled library part requests and tracking. This electronics component information system with BOM/Part List Analysis and tracking capabilities is deployed and available for WR and JTA use. 


\section{Purchased Products/Receiving Inspection Reporting}

eCIS met another opportunity by providing Purchased Product Engineers needed data from multiple systems tailored to individuals or groups to manage their business. Reports were generated from the data in eCIS for engineers to track and manage their workload. For Example:The Expected Receipt Report reduced delays in Receiving Inspection (RI) caused by incomplete engineering documentation (packet makeup) by notifying engineers when parts were expected and had deficiencies in NX, MES Routing, Item Setup, BOM count, LTR, or Test Decision Codes.

Receipt Report to Quality Engineer notified engineers if documentation was missing when parts are received. This report and process has a cost savings of $\$ 128 \mathrm{~K}$. Due to issues, CER information added to expected receipts report to notify engineers of product coming in that did not have a released CER. Links to matrix data were created to view AER, CER, QER, SIERs so that a user did not have to go to another system to get data on the part they are already looking at. Additional Reports:

- CASL - Consilidated Approved Supplier List Report

- NCR Cycletime Report

- RI Cycletime Report

- PATF Prediction Report

- CATS, Open PID, Defects Reports

- PATF \& PPA History \& Graphs on SQESWeb

\section{Computerized QRs, Computerized NCRs and Certified QRs}

Computerized Quality Reports (QRs), Computerized Non-Conformance Reports (NCRs) and Certified QRs directly benefited the weapon programs. The applications were written for E00 to allow engineers in the field to update internal KCP databases with 'real-time' inspection information via a secure web page replacing a time consuming and error prone manual process to generate QRs. Prior to this change, Field Reps sent their reports to KCP via U.S. mail and KCP admins then manually input the information into the database. This project resulted in a combined cost savings of over $\$ 100 \mathrm{~K}$.

Technical challenges included:

- Determining best method to securely access KCP databases through the firewall

- Limiting access by requiring specific information at login

- Doing "on the fly" calculations and error checking of input data

- Pre-populating many fields on the form with data from ERP based on the Part Number

- Limiting scope of available input data to be part number specific

- Getting access to the necessary KCP accounts and servers

- Allowing a draft version to be saved for later retrieval when only preliminary information is available 
Benefits of Computerized QR capability included: overcoming the inability to update internal databases directly from outside the firewall; eliminating the lag time build into the old system; reducing manual entry and eliminating duplicate entry of the data; and eliminating incorrectly calculated numbers. Several fields of the form are pre-populated based on the PO/Part Number combination - reducing potential errors and the input page was designed to look like the existing paper form, thus reducing the learning curve (see Figure 29). Customer feedback has been very positive. The Computerized QR capability was leveraged to implement certified supplier QRs. Computerized NCRs followed to automatically generate a form to create an NCR when defects are observed during the inspection process.

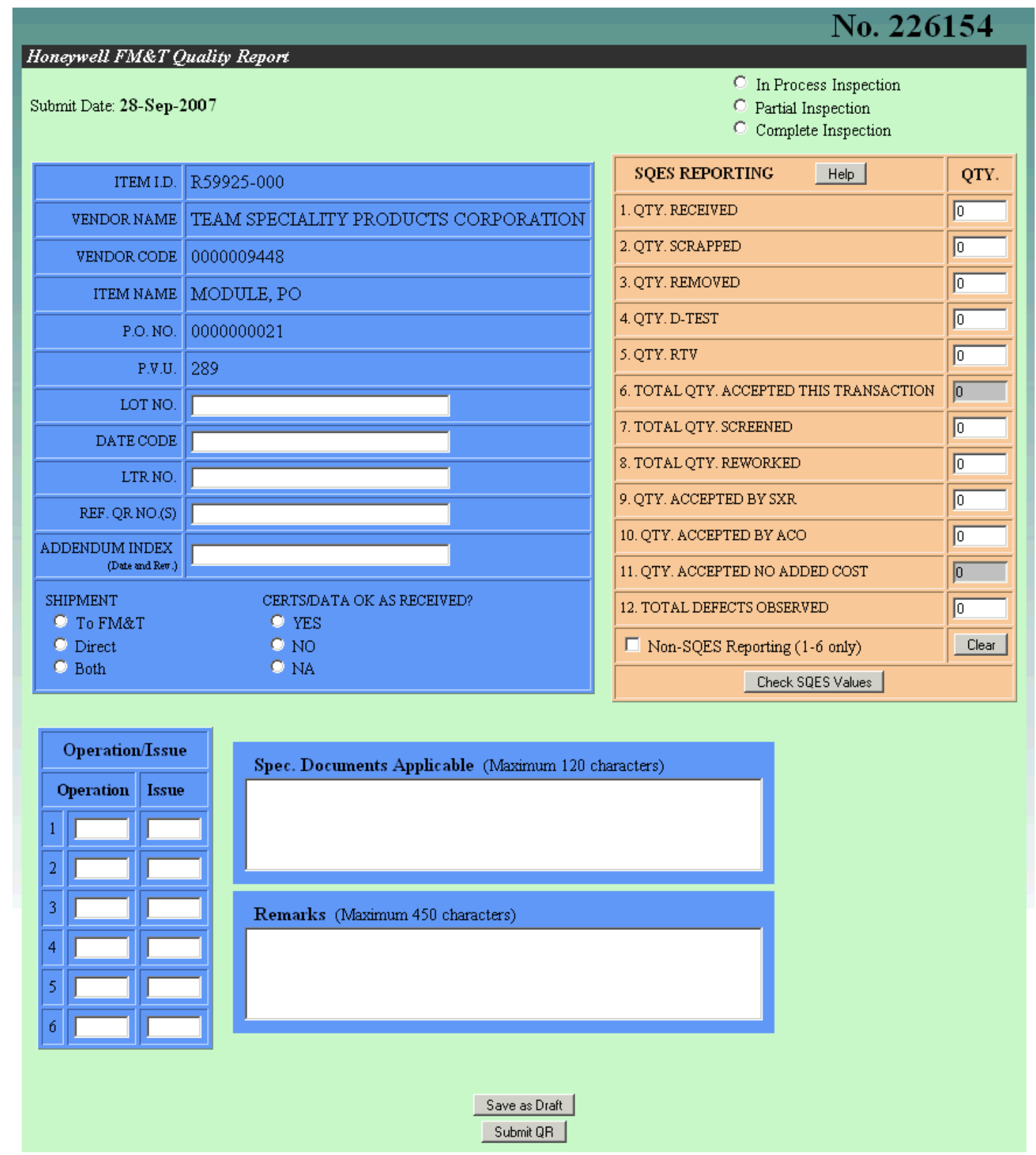

Figure 29. Computerized QR Form 


\section{Failure Analysis, Evaluation and Test Capabilities}

Due to the change in technology with COTS components, equipment had to be purchased to support in-house failure analysis and new component evaluation activities. Compared to the traditional SA device, little was known about the structure of these commercial devices. Methods to perform non-destructive and destructive analysis of COTS components had to be developed. COTS equipment procurement provided KCP with new component evaluation and packaging capabilities unique to COTS. A list of equipment and capabilities include:

- Scanning Acoustic Microscope (SAM) - SAM equipment provides a non-destructive method of finding voids or cracks in the encapsulation molding of COTS component packaging. Failure analysis of COTS components routinely begins with this nondestructive test. Also, Pre and Post SAM testing occurs in qualification of COTS to determine if the qualification environment caused packaging damage to the components.

- Hi Resolution Digital X-Ray - Digital X-Ray equipment is used as a non-destructive method of viewing internal construction of COTS. The digital X-Ray provides a much improved resolution image over film type X-Rays.

- Dual Acid Decapsulation System - Decapsulation of plastic epoxy molding compounds of COTS component packaging is required to perform failure analysis of wire bonding and/or die defects. This equipment allows for the epoxy decapsulation to occur in a controlled time/acid process which provides a consistent epoxy removal approach with minimizing damage to the wires or die.

- LCR Meters - Bench top failure analysis equipment is used to measure inductance, capacitance, and resistance for multiple COTS commodities at needed measurement ranges.

- $1 \mathrm{GHz}$ Oscilloscopes - Engineering and failure analysis capability to characterize and analyze high frequency COTS components.

- Infrared Video Imaging - Portable infrared video camera provides a method of detecting and mapping heat-producing faults in electronic components in real time. This equipment helps provide a quick assessment of failures in semiconductor devices and in passive electronic devices.

- Micro Probe FA Station - This was an upgrade to an existing probe station and provides the optical resolution and probe movement resolution required to perform electrical probing of small geometry semiconductor devices. 
- Semiconductor Characterization System - This bench top equipment performs parametric characterization and failure analysis testing of purchased semiconductor and passive components and provides digital out-put that can be shared and stored on server databases such as eCIS. The tester is an integrated system consisting of a Windows based operating system, source-measuring units (SMUs), and expansion slots for up to 6 additional SMUs. Software applications include a user library, configuration utility, and a graphics interface for test configuration. This data will allow for the failure analysis technologist to import test data directly into a failure analysis report in the form of graphs and data spreadsheets. This will greatly enhance the utility and clarity of the information supplied to the customers of the failure analysis laboratory. New and future programs are planning to use new technology semiconductor devices. This equipment will provide a system that will supply data that can be used to characterize these newer devices.

- Digital IC and Analog IC Bench Testers - These testers help provide electrical test capability for COTS digital and analog Integrated Circuits (IC). Both testers can be used to perform failure analysis and characterization testing against a number of part data sheet requirements.

- Capacitor Burn-In \& Life Test Chamber - A Burn-in/life test chamber used for testing capacitors against requirements of MIL-PRF-123. Forecasts for new commercial parts which are in chip surface mount packages will require qualification life testing.

- Bag Vacuum Sealers - Storage bag vacuum sealers provide the capability to store moisture sensitive COTS components in a dry environment. The sealers are used in multiple areas which receive, store, and use COTS components.

- Temperature 2 Zone Cycle Chamber and HAST System - Air to air thermal shock/cycle testing and Highly Accelerated Stress Test (HAST) provide capability for testing COTS components per industry standards (Mil-Std, JEDEC, etc.) and next assembly environmental requirements. In the event of failed components at the next assembly level, the temperature cycle chamber and the HAST system can be used to assist in performing failure analysis. 


\section{Lessons Learned and What Worked Well}

New processes were identified and developed in order to select, assess, purchase and qualify COTS parts for WR applications. With the developed processes comes the need to better institutionalize all processes for their use in future programs. The WRCIP requires continuous improvement to keep up with industry. A summary of lessons learned include:

- Need refined process to allow buying of parts (LOPB's) and establishing qualification capabilities during development for shortest schedule and fewer problems in qualification

- Need formal schedule plan with tracking and reporting process for each part from beginning

- Discovered that there is a large variation in time to execute major tasks and a large variation in slack time between tasks

- Need quicker response processes for failed items and changes that need to be made during qualification

- Base qualification tests can be an overstress. A combination of $130^{\circ} \mathrm{C}$ and $85 \% \mathrm{RH}$ creates hygroscopic stresses which can damage parts.

- Temperature Cycle and thermal shock test conditions can be beyond component ratings which requires lower temperature range and increased cycles.

- Moisture sensitivity to solder reflow caused additional qualification failures that had to be sorted out (manufacturers advertised MSL 1, but some parts were less than a MSL 1 and had to be treated as MSL3)

- As parts get more complex, the program will need to prepare for handling higher MSL levels in the future

- Qualification tests worked well for many parts and succeeded in finding weaker parts and parts that manufacturers changed from development to production procurement

- Some environmental extremes created failure modes not expected to occur under stockpile conditions (too accelerated for eutectic die attached parts, i.e.)

The WRCIP is a story of success. Over 340 COTS part numbers were qualified in time to support weapon deliverables. Overall qualification using an outside test subcontractor worked well. Communication between KCP and SNL engineering fostered a good working relationship and the ability to resolve technical issues in a timely manner. eCIS tools allowed for timely review of data and easy accessibility helping to facilitate the release of QER's. The COTS Program is developing the knowledge, processes, and infrastructure that COTS components can be used in high reliability systems while meeting performance and cost constraints and managing risk. COTS is a balance of risk and cost. 


\section{References}

1. Marchiondo, et al., W76-1 COTS Characteristics and Development Report, Sand2007-5313, August 2007

2. Wavrik and Aragon, Recommendation memo on Solderability, February, 29, 2006. 


\section{Appendix A: Acronyms}

\section{$\underline{A, B, C}$}

ACO Advance Change Order (used to revise any drawing)

AER Advance Engineering Release - Authorizes in advance PA to prepare for production before receive funding

AFS Arming Fusing Subsystem

Ag Silver

AML Automatic Material List

$\mathrm{Au} \quad$ Gold

AY Graphic Drawing

B-Item Item with an approved source for procurement; documented with SIER/B (Ref: TBP-301; AJ277171)

BOM Bill of Materials

CASL Consolidated Approved Supplier List

CA Construction Analysis

CAD Computer Aided Design

CATS Corrective Action Tracking System

CE Component Engineer

CER Complete Engineering Release [done by SNL CE; defines the complete product definition and will release any drawings not yet released; at a minimum will include a part number, ML, and PS (or AY); must be released before QER; PS must be finalized before CER can be released]

COTS Commercial Off-The-Shelf (parts)

CSAM C-mode Scanning Acoustical Microscope

$\underline{D, E, F}$

DA Design Agency (SNL)

DCS Designated Calibration Source

DE Design Engineer

DPA Destructive Physical Analysis

DOE Department of Energy

DSCC Defense Supply Center Columbus

DTER Drawing Transfer Engineering Release (includes ML and PS numbers; used to transfer production definition originals from DA to PA for origination and maintenance, or to return them to the DA; not a required release but recommended in WRCIP)

D-Test Destructive Test

eCATT Electronic Component Analysis and Test Tracking database (tool at SNL used to define and track electronic part tests and analyses) 


\begin{tabular}{|c|c|}
\hline eCIS & $\begin{array}{l}\text { Enterprise Component Information System (tool at both KCP and SNL with a } \\
\text { parts database, a parts data tracker, and workflow capability) }\end{array}$ \\
\hline EDMA & Electronic Design and Manufacturing Automation \\
\hline eDPA & Enhanced Destructive Physical Analysis \\
\hline EE & $\begin{array}{l}\text { Engineering Evaluation - Process used to assess product in order to qualify it for } \\
\text { a particular application; can be documented in an EER or PQ (Ref: TBP-404) }\end{array}$ \\
\hline EER & $\begin{array}{l}\text { Engineering Evaluation Release (defines the qualification plan; includes plans for } \\
\text { evaluating or re-evaluating product and/or acceptance equipment; specifies } \\
\text { participants, quantities, activities, schedules, procedures, and methods of } \\
\text { evaluation for product and/or processes) }\end{array}$ \\
\hline ER & Engineering release \\
\hline ERP & $\begin{array}{l}\text { Enterprise Resource Planning (PeopleSoft tool at KCP used for item setup and } \\
\text { schedule planning) }\end{array}$ \\
\hline ESR1 & $\begin{array}{l}\text { Evaluation Status Release } 1 \text { (done by SNL QE with concurrence of PRT to verify } \\
\text { the customer's evaluation requirements) }\end{array}$ \\
\hline ESR2 & $\begin{array}{l}\text { Evaluation Status Release } 2 \text { (done by SNL QE; releases the qualification plan as } \\
\text { defined by the EER) }\end{array}$ \\
\hline ESR3 & $\begin{array}{l}\text { Evaluation Status Release } 3 \text { [released when all EER, design and process } \\
\text { requirements (CER) and special test requirements (if any) are met] }\end{array}$ \\
\hline ESR4 & $\begin{array}{l}\text { Evaluation Status Release } 4 \text { (released when all requirements of the ESR3? Are } \\
\text { met and after any ACOs, FCOs, and SXRs are released) }\end{array}$ \\
\hline FA & Failure Analysis \\
\hline $\mathrm{FCO}$ & Final Change Order (may be used to revise the PS) \\
\hline FPU & First Production Unit \\
\hline FTP & File Transfer Protocol \\
\hline
\end{tabular}

\section{$\underline{G, H, I}$}

GE Drawing General Engineering Drawing (used for LoPB calculator)

HALT Highly Accelerated Life Testing (used to determine fault points in assemblies)

HASS Highly-Accelerated Stress Screening

HI-REL High Reliability - Denotes quality level

HTOL High Temperature Operating Life Test

IC Integrated Circuit

IER Information Engineering Release (a general ER typically used to release the

IHS Information Handling Services (Software vendor for technical reference data on

electronic and electromechanical commercial and military parts)

$\begin{array}{ll}\text { IMA } & \text { Initial Manufacturer Assessment } \\ \text { IMS } & \text { Image Management System (drawing system at SNL) }\end{array}$

IPC/JEDEC Standardization bodies

IRA Initial Reliability Assessment

ISO International Standards Organization

Item Setup A process used at the PA to put an item into the ERP 


\section{$\underline{J, K, L}$}

JPL Jet Propulsion Lab

JTA Joint Test Assembly

KCP Kansas City Plant

LANL Los Alamos National Laboratory

LOPB Life of Program Buys (also LoPB)

LTR Laboratory Test Request for lab to examine parts / material

\section{$\underline{M, N, O}$}

M\&TE Measuring and Test Equipment

MES Manufacturing Execution System; instructions for measuring and controlling production activities

MIL-SPEC Military specifications for building parts (Mil-Spec)

MIL-PRF Military performance specifications

ML Materials List

MOSFET Metal Oxide Semiconductor Field Effect Transistor

MSL Moisture Sensitive Level

MSR Material Stock Request

NASA National Aeronautics and Space Administration

NAVSEA Naval Sea Systems Command

NCR Non-Conformance Report

$\mathrm{Ni} \quad$ Nickel

NNSA National Nuclear Security Administration

NPI New Part Introduction (tool to put a new part into the eCIS NWC part database)

NWC Nuclear Weapons Complex

NX Addendum Index that lists drawings, documents, equipment needed for inspection

\section{$\underline{P, Q, R}$}

$\begin{array}{ll}\text { PA } & \text { Production Agency (KCP) } \\ \text { PATF } & \text { Percent Accepted Trouble Free } \\ \text { Pb } & \text { Lead } \\ \text { PCB } & \text { Printed Circuit Board } \\ \text { Pd } & \text { Palladium } \\ \text { PD } & \text { Process Description } \\ \text { PDM } & \text { Product Data Management (Matrix tool at KCP used for product definition and } \\ & \text { engineering release management) } \\ \text { PDT } & \text { Parts Data Tracker } \\ \text { PEM } & \text { Plastic Encapsulated Micorcircuits } \\ \text { PID } & \text { Product Identification } \\ \text { PMIW } & \text { Purchase Material Inspection Worksheet } \\ \text { P/N } & \text { Part Number } \\ \text { PO } & \text { Purchase Order }\end{array}$




$\begin{array}{ll}\text { POQR } & \text { Purchase Order Quality Requirements (released after PA CE does item setup) } \\ \text { PQR } & \text { Product quality requirements } \\ \text { PPA } & \text { Percent Parts Accepted } \\ \text { PPD } & \text { Purchased Product Definition } \\ \text { PPI } & \text { Process Prove-in } \\ \text { PRP } & \text { Product Realization Process } \\ \text { PRT } & \text { Product Realization Team } \\ \text { PS } & \text { Product Specification (defines product acceptance requirements); for COTS parts } \\ & \text { can use instead of AY) } \\ \text { PWA } & \text { Printed Wiring Assembly } \\ \text { PWB } & \text { Printed Wiring Board } \\ & \text { Quality Engineer } \\ \text { QE } & \text { Qualification Evaluation Release [released after ESR4 is released and have } \\ \text { QER } & \text { qualified readiness for production; should specify which program(s) and MC(s) } \\ & \text { for which the device is qualified for use] } \\ \text { QPA } & \text { Quick Part Assessment } \\ \text { QR } & \text { Quality Report } \\ \text { Qual } & \text { Qualification } \\ & \\ \text { RAD } & \text { Radiation } \\ \text { REID } & \text { Re-identification of an item / part } \\ \text { RF } & \text { Radio Frequency } \\ \text { RFP } & \text { Request for Proposal } \\ \text { RH } & \text { Relative Humidity } \\ \text { RI } & \text { Receiving Inspection (at KCP) } \\ & \\ \text { S, T,U } & \\ \text { SA } & \text { SNL Apparatus } \\ \text { SAM } & \text { Scanning Accoustic Microscope } \\ \text { SCD } & \text { Source Control Drawing } \\ \text { SIER } & \text { Special Instruction Engineering Release [authorizes specific actions to be taken } \\ & \text { by the PA (e.g., written if ESR2 requirements cannot be met and further special } \\ \text { SIER/B } & \text { tests are required) } \\ \text { BLEP item designation to document sole source; must be signed by SNL CE manager } \\ \text { Sn } & \text { Stockpile Life Extension Program } \\ \text { SNL } & \text { Tin } \\ \text { SNLA } & \text { Sandia National Laboratory } \\ \text { SNLL } & \text { Sandia National Laboratory - Albuquerque } \\ \text { SOW } & \text { Sandia National Laboratory - Livermore } \\ \text { SPUDS } & \text { Scope of Work or Statement of Work } \\ \text { SQES } & \text { SNL Parts Unified Data Source } \\ \text { SRM } & \text { Supplier Quality Evaluation System } \\ \text { SS } & \text { Supplier Relationship Management (eCIS - Software Module from i2 } \\ & \text { Technologies) } \\ & \\ & \text { System Specification or Special Use Specification } \\ & \end{array}$


Stores Refers to location of material at KCP that has been accepted; includes production and non-production material at KCP that is not in inspection or production

SXR Special Exception Release (used to document any exceptions to the EER plan and/or any additional information determined in the SIER plan)

T-Cycle Temperature Cycle or Temp Cycle

T-Shock Thermal Shock or Temp Shock

TBP Technical Business Practice

TDT Test Data Tracker

User AER Advance Engineering Release from Designer (this is an optional release for advanced production planning; it has a board level approved part list with specified quantities, i.e., next assembly agrees to use the part prior to production and defines the quantity to be used)

\section{$V, W, X, Y, Z$}

VIP

$$
\text { Very important parts }
$$

WI Work Instruction

WR War Reserve

WRCIP War Reserve COTS Insertion Process 


\section{Appendix B: Outline Scope of Work for Outside Test House}

- Quality Requirements

- PQR-1040 Approved

- PQR-2676 Approved

- M\&TE Reviews

- Program Management

- Designated Program Manager

- List of Seller personnel working on Buyer Product

- Notification of test failures within one working day

- Prioritization of testing on Buyer product

- Right to stop testing when failure occurs

- Resident Buyer Representative

- Current Status Available for All Product

- Part Handling

- Handle products per SS1A3023

- Nitrogen storage capability

- Tinning per SS1A3022

- Seller responsible for product

- Control samples

- Part Storage and Control

- Temperature and Humidity control per PQR-1040

- Buyer option to forward balance of product

- Access to Buyer product

- Methods and facilities for ID, handling and storage of product to meet PQR-1040

- Buyer approval in writing for moisture bakeout

- Configuration Management / Buyer Approvals

- Test Flow approvals

- Electrical Test Software approvals

- Hardware diagrams

- Electrical test fixtures

- HAST boards

- Burn-in Boards

- Hardware and Software revision control

- Equipment studies

- Data Management

- Electronic Data Transfer

- Control of Quality Records

- Data format for all data 
- Subcontractor Management

- Seller to evaluate, select and control Subcontractors per PQR-1040

- List all subcontracted testing required to test parts in Appendix A

- List of Seller approved Subcontractors

- Buyer access to Subcontractor facilities

- Buyers rights at Subcontractors:

- Perform PQR-1040 audits

- Perform Process Audits

- Verify Equipment Calibrations

- Perform Equipment Studies

- Right to disallow use of a Seller approved Subcontractor

- Seller Furnished Equipment / Materials

- Hardware and Software necessary to perform testing

- Materials used for testing product

- Identify method used to meet this requirement

- Buyer Furnished Property

- Product to be tested

- Shipping damage

- Drop shipment of product

- Deliverables and Expectations

- Seller determines most cost effective method for testing

- Minimum report

- Supplier product data

- Documentation and Data identification

- Lot Summary data - .pdf or Excel format

- Test Flows used for testing / inspection - .pdf or Excel format

- Attributes data for all testing

- Variables data with statistics - Excel format

- DPA and SAM results - .pdf or Word format

- All electronic data to be provided on CDROM

- Disposition of Product and Testing

- D-Test product - Sent to Buyer Rep as designated by Buyer

- Rejected product - Buyer to provide instructions

- Packaging

- Handle, package and store per SS1A3023

- Package for shipment per 1464202 Method \#1 


\section{Appendix C: Technical Merit Factors for Test House Selection}

- Management \& Staff

$10 \%$

o Organization Chart

o Resume of Key Management Personnel

o Involvement of Each Person Identified

o Specify Primary Testing House Location

o Indicators of Financial Stability

- Company Experience

$15 \%$

o Examples of 2 Test Service Projects similar in Scope and Magnitude

- Company

- Duration

- Value of Contract

- Description

o Number of Full Time Employees at Primary Location

o Evaluation of Past Performance

- Performance

- Communication

- Delivery

- References

o Contacts for 2 Companies

$5 \%$

o Buyer May Communicate with References

- Customer Service

- Responsiveness

- Flexibility

- Communication

- Invoice Accuracy

- Overall Performance

- Scope of Work $30 \%$

o Response to Statement of Work

o Compliance to Requirements

o Assessment of Ability to Accomplish Tasks in SOW

- Presentation of Proposal 10\%

o On Site Presentation addressing Statement of Work

o Graded on Ability to address Content of

- Contract Proposal

- Statement of Work

- Technical Evaluation Criteria 